Portland State University

PDXScholar

$11-2016$

\title{
Does Local Religiosity Affect Organizational Risk- taking? Evidence from the Hedge Fund Industry
}

Lei Gao

lowa State University

Ying Wang

State University of New York at Albany

Jing Zhao

Portland State University

Follow this and additional works at: https://pdxscholar.library.pdx.edu/busadmin_fac

Part of the Organizational Behavior and Theory Commons

Let us know how access to this document benefits you.

\section{Citation Details}

Gao, L., Wang, Y., \& Zhao, J. (2017). Does local religiosity affect organizational risk-taking? Evidence from the hedge fund industry. Journal of Corporate Finance, 47, 1-22.

This Post-Print is brought to you for free and open access. It has been accepted for inclusion in Business Faculty Publications and Presentations by an authorized administrator of PDXScholar. Please contact us if we can make this document more accessible: pdxscholar@pdx.edu. 


\title{
Does Local Religiosity Affect Organizational Risk-taking? Evidence from the
}

\author{
Hedge Fund Industry*
}

\author{
Lei Gao \\ Ying Wang \\ Jing Zhao
}

This version: November 2016

\begin{abstract}
We examine the impact of local religious beliefs on organizational risk-taking behaviors using hedge funds as a new and unique setting. We find that local religiosity is significantly negatively related to both total and idiosyncratic volatilities of hedge funds during 1996-2013, even after controlling for endogeneity using managers' college-location religiosity. Consistent with the local preference channel, the impact of local religiosity on risk-taking is only pronounced among funds for which local managers and investors are more important, namely semi-directional, young, and small funds. Further, hedge funds located in more religious counties tend to hold less risky stocks and diversify their stock portfolios across industries, thus contributing to lower hedge fund risk-taking. Overall, our evidence suggests that local religiosity may motivate hedge fund managers to reduce risk.
\end{abstract}

Keywords: Local religiosity, organizational risk-taking, hedge fund, idiosyncratic risk, local preference

\footnotetext{
* Gao is at Department of Finance, Iowa State University, 3342 Gerdin Business Building, Ames, IA 50011; lgao@iastate.edu; (515) 294-7860. Wang is at School of Business and Center for Institutional Investment Management, State University of New York at Albany, 365 Massry Center for business, Albany, NY 12222; ywang@albany.edu; (518) 956-8357. Zhao is at School of Business Administration, Portland State University, PO Box 751, Portland, OR 97207; jingzhao@pdx.edu; (503) 725-8366. We thank Bill B. Francis, Charles Knoeber, Srini Krishnamurthy, Blake Phillips, Saurin Patel, Yinjie Shen, Tom Shohfi, Zhipeng Yan, and participants at Eastern Finance Association Annual Meeting, Midwest Finance Association Annual Meeting, World Finance Conference, Rensselaer Polytechnic Institute, and University at Albany’s Financial Market Symposium for helpful comments and suggestions. We are especially grateful to Eastern Finance Association 2016 Annual Meeting for selecting an earlier version of this paper entitled "Local Religious Beliefs and Hedge Fund Risk-Taking Behaviors" as the winner of an Outstanding Paper Award.
} 


\title{
Does Local Religiosity Affect Organizational Risk-taking? Evidence from the
}

\author{
Hedge Fund Industry
}

\begin{abstract}
We examine the impact of local religious beliefs on organizational risk-taking behaviors using hedge funds as a new and unique setting. We find that local religiosity is significantly negatively related to both total and idiosyncratic volatilities of hedge funds during 1996-2013, even after controlling for endogeneity using managers' college-location religiosity. Consistent with the local preference channel, the impact of local religiosity on risk-taking is only pronounced among funds for which local managers and investors are more important, namely semi-directional, young, and small funds. Further, hedge funds located in more religious counties tend to hold less risky stocks and diversify their stock portfolios across industries, thus contributing to lower hedge fund risk-taking. Overall, our evidence suggests that local religiosity may motivate hedge fund managers to reduce risk.
\end{abstract}

Keywords: Local religiosity, organizational risk-taking, hedge fund, idiosyncratic risk, local preference 


\section{Introduction}

There has been a growing literature on the impact of local culture, particularly local religious beliefs, on organizational risk-taking behaviors. In general, theoretical studies predict a negative effect of local religiosity on organizational risk-taking based on two premises. First, sociologists and psychologists have long recognized that individuals are likely influenced by local culture and beliefs through social interactions, which in turn reinforce individual preferences such that they share the same identity with each other (Tajfel (1978) and Hogg and Abrams (1988)). Second, prior research (e.g., Osoba (2003) and Hilary and Hui (2009)) has established a robust association between religious beliefs and individuals' risk aversion, likely due to the fact that most religions teach their followers to prioritize spiritual endeavors over monetary gain which typically requires taking financial risks. To the extent that local religiosity induced risk aversion affects an organization's key stakeholders, local religiosity can exert a negative impact on organizational risk-taking behaviors.

Despite clear theoretical predictions, the empirical evidence has provided mixed results. For instance, existing literature documents that local religiosity negatively affects risk taking by non-financial firms (Hilary and Hui (2009)) and banks (Adhikari and Agrawal (2016b)). However, Shu, Sulaeman, and Yeung (2012) show that a sample of growth and aggressive growth mutual funds located in more religious areas tend to undertake more risk. ${ }^{1}$

In this paper, we aim to shed light on the effect of local religiosity on organizational risktaking using hedge funds as a new and unique setting. Specifically, we examine whether and how local religious beliefs affects hedge fund managers' risk-taking behaviors.

\footnotetext{
${ }^{1}$ Shu et al. (2012) document that total religiosity is significantly positively related to mutual fund total and idiosyncratic risk, although they focus on the effects of different religious groups (i.e., Catholics versus Protestants) on mutual fund risk taking. For completeness, we also discuss different religious groups in Section 3.7.
} 
We focus on hedge funds for several reasons. First, hedge funds have many unique features which may mitigate the potential effect of local religiosity on their risk-taking, thus offering an ideal setting for our purpose. For instance, compared to mutual funds, hedge fund managers have stronger financial incentives to make profits as they are typically paid a significant portion of excess returns as performance fees (e.g., 20\%) in addition to fixed management fees. They also invest a considerable amount of personal wealth into their own funds. And they face extraordinary competition from their peers and are under constant pressure to deliver superior performance. All these features may motivate hedge fund managers to focus on performance-maximizing investment strategies, which are culturally invariant. In addition, compared to mutual funds, hedge funds have more flexibility and less constraints in risk-taking so that the impact of local culture on hedge fund investment decisions is likely to be minimal. In particular, hedge funds are lightly regulated and not required to hold diversified portfolios so they can take large and concentrated stakes in individual firms more easily; they also face fewer conflicts of interests than mutual funds who may have other business relations with the invested companies; and they have lock-up provisions that restrict the investors from withdrawing their principal over certain lock-up periods. Overall, these unique features make hedge funds least likely to be affected by local religiosity, if any. Therefore, if we document significant evidence in the hedge fund industry, it will provide strong support for the impact of local religious beliefs on organizational risk-taking.

Second, despite the tremendous growth of the hedge fund industry over the past two decades $^{2}$ and a growing literature on hedge funds, the effect of local religious beliefs, an important aspect of local culture, on hedge fund risk-taking behaviors has never been explored.

\footnotetext{
${ }^{2}$ According to Hedge Fund Research (HFR), the total assets under management (AUMs) by global hedge funds have increased dramatically from $\$ 50$ billion in 1990 to $\$ 3$ trillion in 2015 .
} 
Notably, while existing literature has focused on fund-, strategy-, and market-specific determinants of hedge fund risk-taking (e.g., Fung and Hsieh (1997), Brown, Goetzmann, and Park (2001), Chen (2011), Aragon and Nanda (2012), and Smith, Wang, Wang, and Zychowicz (2016)), human behavior is still a missing piece. This is particularly surprising given the importance of understanding the risk-taking incentives of hedge funds, which are frequently blamed for causing systemic risk during financial crises such as the 1998 Long Term Capital Management debacle and 2007-2009 financial crisis. Indeed, anecdotal evidence suggests that human behavior plays an important role during financial crises. ${ }^{3}$ Our paper fills the gap in the literature by investigating the role of one specific aspect of human behavior, namely local religiosity induced risk aversion, in explaining hedge fund risk-taking. ${ }^{4}$

Finally, unlike mutual funds, hedge funds have various investment strategies, such as directional, semi-directional, and non-directional strategies. While directional funds (such as macro) take direct market exposure and risk, semi-directional funds (such as equity hedge and event-driven) tend to diversify market risk by taking both long and short, diversified positions, and non-directional funds (such as equity market neutral) aim to minimize market risk altogether. These strategies also differ significantly in the roles hedge funds' key local stakeholders may play in determining hedge fund risk-taking. For instance, Sialm, Sun, and Zheng (2014) suggest that semi-directional funds are most likely to be affected whereas directional funds are least likely to be impacted by local investor preferences. Therefore, it would be interesting to see whether local religiosity has different effects on the risk-taking behaviors of various hedge fund

\footnotetext{
${ }^{3}$ For instance, in a testimony to the U.S. House of Representatives Committee on hearing on hedge funds, Lo (2008) attributes financial crises to be "a consequence of the interactions between hardwired human behavior and the unfettered ability to innovate, compete, and evolve."

${ }^{4}$ One caveat is that religiosity might have implications other than risk aversion, thus resulting in a measurement error. However, as argued in Adhikari and Agrawal (2016b), any resulting attenuation bias should only bias us against finding significant results.
} 
strategies, especially given that Shu et al. (2012) only focus on a sample of growth and aggressive growth mutual funds.

To the extent that local religiosity may affect the risk preferences of hedge fund managers and investors, we hypothesize that hedge funds located in more religious areas are less likely to take risk. For instance, hedge fund managers are often local or conform to local cultural and religious forms. Moreover, the literature on local bias suggests that hedge funds tend to hold more local stocks in their portfolios (Teo (2009)), and they can benefit from catering to local investor preferences (Sialm et al. (2014)). As a result, higher local religiosity may induce higher risk aversion of hedge funds' managers and investors, thus resulting in lower risk-taking. The alternative hypothesis is that local religiosity has no effect on the risk-taking behaviors of hedge funds due to their unique features as discussed earlier.

Using a sample of 7,033 hedge funds from the HFR database and county-level religiosity data during 1996-2013, we find that local religiosity is significantly negatively related to hedge funds' total and idiosyncratic return volatilities. This result appears to be primarily driven by the semi-directional strategies such as equity hedge and event-driven, which diversify market risk by taking both long and short, diversified positions.

While our results suggest a negative effect of local religiosity on hedge fund risk-taking (the "local religiosity impact" hypothesis), they may also be driven by endogeneity due to reverse causality in the sense that more risk-averse managers tend to choose funds located in areas with more religious populations (the "self-selection" hypothesis), or due to omitted variables that are correlated with both local religiosity and hedge fund risk-taking. We use a variety of control variables in our regressions and include year and investment strategy fixed effects to control for unobservable, strategy-related, omitted variables. To further establish 
causality, we employ several additional tests. First, we construct two instrumental variables following Hilary and Hui (2009), i.e., the three-year lagged local religiosity and three-year lagged total county population, and undertake an instrumental variables (IV) regression analysis. Second, we follow Wintoki, Linck, and Netter (2012) and perform the dynamic panel generalized method of moments (GMM) estimation. Our results remain robust after controlling for endogeneity using both IV and GMM estimations.

To further alleviate concerns over reverse causality, we use local religiosity of hedge fund managers' undergraduate college locations to proxy for their innate religious beliefs and conduct a horse-race analysis on the effects of college- versus fund-location religiosity on hedge fund risk-taking. Our results show that fund-location religiosity indeed dominates collegelocation religiosity in mitigating managers' risk-taking. And this effect is more pronounced if the college location is in a different region than the fund location. While we cannot completely rule out the "self-selection" hypothesis, these tests provide additional evidence that after controlling for reverse causality, local religiosity has a significant negative impact on managers' risk-taking behaviors, thus lending further support for the "local religiosity impact" hypothesis.

Further, we find that the risk mitigating effect of local religiosity exists for both financial crisis and non-crisis periods but appears to be stronger during crisis periods, when it is most important and needed, i.e., during time periods with excessive risk-taking and uncertainty. The results are also robust to excluding hedge funds located in New York (the top one state of hedge fund concentration, which constitutes $38 \%$ of our sample funds), suggesting that our findings are not driven by the state with the greatest hedge fund concentration. However, we do not find that local religiosity affects hedge fund performance as proxied by the Nine-Factor (a combination of Carhart (1997) four factors and Fung and Hsieh (2004) seven factors) Alpha. 
We next explore the local preference channel through which local religiosity may affect hedge fund risk-taking. The evidence suggests that the effect of local religiosity on the risk preferences of local managers and investors may, at least partially, help explain our findings. Specifically, we find that the negative relation between local religiosity and risk-taking is only pronounced among funds for which local managers and clients are economically more important, i.e., semi-directional (such as equity hedge) rather than directional (such as macro), young rather than old, and small rather than large funds.

Finally, analyses of hedge fund holdings show that funds located in counties with higher religiosity ratios tend to hold less risky stocks and diversify their stock portfolios across industries, thus contributing to lower hedge fund return volatilities.

We make several important contributions to the literature. First, to the best of our knowledge our study is the first in the hedge fund literature to examine the effect of local culture, particularly local religious beliefs, on hedge fund risk-taking behaviors. Second, this paper is part of a growing literature on the effects of local religiosity on organizational risk-taking (e.g., Hilary and Hui (2009), Kumar, Page, and Spalt (2011), Shu et al. (2012), and Adhikari and Agrawal (2016b)) and involvement in questionable activities (e.g., Grullon, Kanatas, and Weston (2009), Dyreng, Mayew, and Williams (2012), McGuire, Omer, and Sharp (2012), Boone, Khurana, and Raman (2013), Callen and Fang (2015), and Adhikari and Agrawal (2016a)). ${ }^{5}$ Finally, we contribute to the literature on portfolio location and home bias. While prior studies examine the potential advantages (e.g., lower monitoring and information acquisition costs) of a

\footnotetext{
${ }^{5}$ Economists and sociologists have long documented significant effects of religious beliefs on various social behaviors: marriage (Lehrer and Chiswick (1993)), divorce (Heaton and Pratt (1990)), crime (Evans, Cullen, Dunaway, and Burton JR. (1995)), suicide (Bainbridge (1989)), and drug and alcohol consumption (Cochran and Akers (1989)). Until more recently, financial researchers have examined the effects of religion primarily at the macro level, such as on government quality (La Porta, Lopez-de-Silanes, Shleifer, and Vishny (1999)), creditor protection (Stulz and Williamson (2003)), and economic growth (Guiso, Sapienza, and Zingales (2003)).
} 
fund due to the geographical proximity to the stocks in its portfolio (Coval and Moskowitz (1999) and (Coval and Moskowitz (2001)), we document that location may also affect hedge fund behaviors through local culture.

It is worth noting that our paper differs from, as well as complements, Shu et al. (2012) in several aspects. First and foremost, unlike Shu et al. (2012) who suggest a positive relation between local religiosity and mutual fund risk-taking, we document that local religiosity mitigates hedge fund risk-taking, and this negative relation is primarily driven by semidirectional strategies. We also show that the difference could be attributed to fund styles. ${ }^{6}$ Second, we establish causality by running a horse-race analysis between managers' college- and fund-location religiosity, to the extent that the former captures managers' innate religious beliefs that are formed prior to coming to the fund's location. Finally, we show that local religiosity mitigates hedge fund risk-taking at both the individual stock and portfolio levels, whereas Shu et al. (2012) document that local religiosity only appears to affect mutual fund risk-taking at the portfolio level. Therefore, while Shu et al. (2012)'s results cannot be attributed to local bias, it is possible that our results are driven by hedge fund managers' local preferences (Teo (2009)).

The rest of the paper proceeds as follows. Section 2 describes the data and provides summary statistics. Section 3 presents our main findings regarding the effect of local religiosity on hedge fund risk-taking. Section 4 explores the local preference channel through which local religiosity may impact hedge fund risk-taking. Section 5 examines how local religiosity affects hedge fund stock holdings and portfolio diversification. Section 6 concludes.

\footnotetext{
${ }^{6} \mathrm{We}$ find that local religiosity is significantly positively related to risk-taking for the most aggressive directional strategies which take direct market exposure and risk, such as macro. This positive relation is indeed consistent with Shu et al. (2012) who use a sample of growth and aggressive growth mutual funds which tend to take more risk.
} 


\section{Data and Measures}

In this section, we first discuss our hedge fund sample and then present county-level religiosity and demographic data. In particular, we describe data sources, sample selection, and variable construction, and provide summary statistics for the key variables used in our analyses.

\subsection{Hedge fund sample}

Our hedge fund data come from the HFR database, which reports fund characteristics and operational data (including business address), along with monthly returns and AUMs. To mitigate survivorship bias, we include both live and graveyard funds located in the US from January 1994 when HFR started to track graveyard funds through December 2013. To ensure that the same fund does not appear multiple times in the database, we only keep funds with net monthly returns denominated in the US dollar. If a hedge fund has both off- and on-shore funds, we keep the fund with the longest return history or the largest asset size. Further, to alleviate backfill and incubation biases, we delete return observations of a fund prior to the date it was added to the database (Aggarwal and Jorion (2010)). ${ }^{7}$ As a result, our sample period is effectively from 1996 to 2013 . We also require a fund to have at least 18 monthly returns during the sample period. Finally, we keep funds with the following primary investment strategies: Equity Hedge, Event-Driven, Fund of Funds, Macro, and Relative Value. Our final sample contains 7,033 hedge funds, of which 2,161 are live and 4,872 are graveyard funds.

Since our focus is on the hedge fund risk-taking behaviors, we estimate two risk measures for individual funds every year using a 24-month rolling window: ${ }^{8}$ (1) Total Risk,

\footnotetext{
${ }^{7}$ Alternatively, we follow Fung and Hsieh (2000), Teo (2011), and Bali, Brown, and Caglayan (2011) and delete the first 18 months of returns of all individual hedge funds in our sample, and our results remain robust.

${ }^{8}$ Our results are robust if we use an 18,36 , or 60 -month rolling window in constructing hedge fund risk measures.
} 
defined as the standard deviation of monthly hedge fund returns; and (2) Idiosyncratic Risk, calculated as the standard deviation of the residuals from the following nine-factor model, in which we combine the Carhart (1997) four factors and Fung and Hsieh (2004) seven factors:

$$
\begin{aligned}
r_{i, t}= & \alpha_{i}+\beta_{i, M K T} M T_{t}+\beta_{i, S M B} S_{M B}+\beta_{i, H M L} H_{M} L_{t}+\beta_{i, U M D} U M D_{t} \\
& +\beta_{i, T E R M} \text { TERM }_{t}+\beta_{i, C R E D I T} \text { CREDIT }_{t}+\beta_{i, P T F S B D} \text { PTFSBD }_{t} \\
& +\beta_{i, P T F S F X} \text { PTFSFX }_{t}+\beta_{i, \text { PTFSCOM }} \text { PTFSCOM }_{t}+\varepsilon_{t},
\end{aligned}
$$

where $r_{i, t}$ is the month- $t$ return on fund $i$ in excess of the one-month T-bill rate; $M K T$ is the market return in excess of the one-month T-bill rate; $S M B$ is the small-minus-big size factor, $H M L$ is the high-minus-low book-to-market factor; $U M D$ is the momentum factor; TERM is a bond market factor defined as the return spread of the Barclays Capital 7-10 year Treasury index and the one-month T-bill rate; CREDIT is a credit spread factor defined as the return spread of the Barclays Capital Corporate Bond Baa Index and the 7-10 year Treasury index; and PTFSBD, PTFSFX, and PTFSCOM are the trend-following factors of Fung and Hsieh (2001) for bonds, currencies, and commodities, respectively. ${ }^{9}$

[Insert Table 1 about here]

Panel A of Table 1 shows that an average hedge fund in our sample has monthly total risk of $3 \%$ and idiosyncratic risk of $1 \%$. This indicates that a large proportion $(33.3 \%)$ of total hedge fund risk is due to idiosyncratic risk. We also observe substantial variations of both risk measures in the full sample. For instance, the $75^{\text {th }}$ percentile is $0.04(0.02)$ for total (idiosyncratic) risk, which is considerably larger than the $25^{\text {th }}$ percentile of $0.01(0.00)$.

\footnotetext{
${ }^{9}$ We thank Ken French and David Hsieh for providing their risk factors on their respective websites: http://mba.tuck.dartmouth.edu/pages/faculty/ken.french/data_library.html and http://faculty.fuqua.duke.edu/ dah7/ Datalibrary/ TF-FAC.xls.
} 
In our analyses, we control for various hedge fund characteristics that are shown in prior literature (e.g.,Chen (2011) and Smith et al. (2016)) to affect hedge fund risk-taking. Panel B of Table 1 reports summary statistics of these fund characteristics (see Appendix A for variable definitions). Approximately $58 \%$ of all hedge funds in our sample use leverage (leverage), and $87 \%$ have a management fee structure that includes a high watermark provision

(high_watermark). On average, the AUMs of a hedge fund (fund_assets) are $\$ 157.52$ million; the AUMs of a hedge fund firm (firm_assets) are $\$ 10$ billion; the lockup period (lockup) is 4.65 months; the advance notice period required for asset redemptions from a fund (advance_notice) is 43 days; annual management fee (management_fee) is 1.44\%; annual incentive fee (incentive_fee) is $16.89 \%$; and the minimum investment required for a fund (minimum_investment) is $\$ 1.3$ million. Further, only $13 \%$ of our sample funds specify a hurdle rate (hurdle_rate), but almost all (92\%) of the funds perform an annual audit (audit).

\subsection{Religiosity and demographic data}

We collect religiosity data from the Association of Religion Data Archive (ARDA). The data set, initially constructed by the Glenmary Research Center and the Association of Statisticians of American Religious Bodies and distributed by the ARDA website, contains county-level religion statistics for 133 Judeo-Christian church bodies every 10 years. Our main variable of interest is the county-level religiosity ratio $(R E L)$, calculated as the total number of adherents of all congregations to the total population in the county as reported by the U.S. Census Bureau. Following prior studies (e.g., Alesina and La Ferrara (2000), Hilary and Hui (2009), and Shu et al. (2012)), for our sample period of 1996-2013, we linearly interpolate 
religiosity ratios between the survey years of 1990, 2000, and 2010 and use the data in 2010 to set the values for the $2011-2013$ period. ${ }^{10}$

Panel $\mathrm{C}$ of Table 1 indicates that an average hedge fund is located in a county with $54 \%$ religious population, which is similar to the U.S. average (55.64\%). There also exists wide variation in religiosity ratios in our sample. For instance, the $75^{\text {th }}$ percentile of religiosity ratio is 0.62 , while the $25^{\text {th }}$ percentile is 0.44 .

We also control for a broad set of demographic variables in our analyses as in previous literature (e.g., Iannaccone (1998), Hilary and Hui (2009), and Shu et al. (2012)). Specifically, we obtain the county-level demographic data from the U.S. Census Bureau for the three years 1990, 2000, and 2010. Appendix A also provides definitions of these demographic variables.

Panel D of Table 1 provides descriptive statistics of county-level demographic variables. For the county where a typical hedge fund is located, the median age of the population (age) is 36 years, the fraction of population who are 25 years or older with a Bachelor's, postgraduate, or professional degree (edu) is $42.63 \%$, the mean per capita personal income (income) is $\$ 58,953$, the total county population (ttlpop) is 1.87 million, the ratio of male to female population $(\mathrm{mf})$ is 0.92 , the proportion of minorities in the total county population (minority) is $38 \%$, and the fraction of married to total households (married) is $16 \%$.

\section{[Insert Table 2 about here]}

Table 2 presents the correlation coefficients among all of the key variables. Specifically, we find that local religiosity $(R E L)$ is significantly negatively correlated with both total and idiosyncratic risk. The correlation coefficients provide preliminary evidence that hedge funds located in more religious counties are more likely to undertake lower total and idiosyncratic risk.

\footnotetext{
${ }^{10}$ As a robustness check, we do not linearly interpolate religiosity data and find similar results.
} 


\section{Empirical Analysis: Local Religiosity and Hedge Fund Risk-taking}

This section presents our main findings regarding the impact of local religious beliefs on hedge fund managers' risk-taking behaviors. We start with a portfolio analysis of excess fund risk measures sorted by local religiosity in Section 3.1, and then perform panel and FamaMacBeth regressions in Section 3.2. Section 3.3 examines the relation between local religiosity and hedge fund risk-taking across various fund investment strategies. In Section 3.4, we attempt to address potential endogeneity concerns using instrumental variables (IV) regressions, dynamic panel generalized method of moments (GMM) estimation, and a horse-run analysis of managers' college- vs. fund-location religiosity. Section 3.5 performs additional robustness tests. Section 3.6 examines whether local religiosity affects hedge fund performance. Finally, we discuss the results across different religious groups in Section 3.7.

\subsection{Portfolio analysis: hedge fund risk-taking sorted by local religiosity}

To investigate the relation between local religiosity and hedge fund risk-taking, we first conduct a portfolio analysis. Each year we sort hedge funds into quintiles based on their local religiosity ratios. To control for investment strategy, we adjust both risk measures of a fund by subtracting the annual median values within the fund's investment strategy to obtain excess total and idiosyncratic risk measures. We then calculate the annual means of these measures for each quintile, and report the time-series averages. We also report the differences between the top and bottom religiosity quintiles and the associated $t$-statistics.

[Insert Table 3 about here] 
Table 3 reports the results. The mean excess Total Risk appears to decrease with local religiosity, although not monotonically. The difference between the highest and lowest religiosity quintiles is $-0.27 \%$, which is statistically and economically significant. We observe a similar pattern for the mean excess Idiosyncratic Risk, although the magnitude is smaller. Taken together, our portfolio analysis suggests that indeed, hedge funds located in an area with more religious populations are associated with lower total and idiosyncratic risk-taking. As these fund managers typically hold an under-diversified wealth portfolio with a disproportionately greater weight invested in the fund they work for (e.g., through either human capital or monetary investment), total and idiosyncratic risk-taking can have substantial impacts on their wealth and utility.

\subsection{Regression analysis of hedge fund risk-taking on local religiosity}

To control for a variety of fund characteristics and county-level demographic variables that may affect fund risk-taking, we perform multivariate regressions of hedge fund risk measures on local religiosity as follows:

$$
\operatorname{HFRisk}_{i, t}=\alpha+\beta R E L_{i, t}+\gamma X_{i, t}+\varepsilon_{i, t},
$$

where HFRisk $k_{i, t}$ is the risk-taking measure (total or idiosyncratic risk) of hedge fund $i$ in year $t$, $R E L_{i, t}$ is the county-level local religiosity ratio of fund $i$ in year $t$, and $X$ contains all control variables such as fund characteristics and demographic factors, as well as various fixed effects. If local religiosity induced risk aversion leads to lower risk-taking of hedge funds, a negative coefficient $(\beta)$ is expected; otherwise an insignificant $\beta$ is anticipated, suggesting that local religion has no effect on hedge fund risk-taking behaviors.

[Insert Table 4 about here] 
In Panel A of Table 4, we run panel regressions including both strategy and year fixed effects to control for any unobservable, omitted, investment strategy-specific factors and variations due to time. ${ }^{11}$ Note that all variables are winsorized at the upper and lower $1 \%$ levels and P-values (in parentheses) are calculated using robust standard errors. We find a significant and negative coefficient on REL for total risk. Economically speaking, a one standard deviation increase in REL (0.11) leads to a reduction of $0.09 \%$ in total risk, which represents $2.9 \%$ of the standard deviation in total risk. For idiosyncratic risk, a one-standard-deviation increase in $R E L$ translates into a decrease of approximately $0.03 \%$ in idiosyncratic risk, representing $1.65 \%$ of the standard deviation in idiosyncratic risk.

Panel B of Table 4 presents Fama-MacBeth (Fama and MacBeth (1973)) regression results. Specifically, we run cross-sectional regressions of hedge fund risk measures on local religiosity each year, and then calculate the time-series averages of regression coefficients. The table shows that local religiosity is significantly negatively related to both total and idiosyncratic volatilities. Indeed, both the statistical significance and economic magnitude of the coefficients on $R E L$ are substantially improved relative to those panel regression results. More specifically, a one-standard-deviation increase in REL $(0.11)$ leads to a reduction of $0.17 \%$ and $0.07 \%$ in total and idiosyncratic risk, respectively, which are equivalent to $5.5 \%$ and $3.3 \%$ of the standard deviation in total and idiosyncratic risk.

The coefficient estimates on control variables are consistent with prior literature (e.g., Chen (2011)). Larger funds or bigger firms are less likely to take risk. The minimum investment is negatively related to fund volatilities. Higher management fee encourages greater risk-taking, whereas higher incentive fee induces managers to undertake more idiosyncratic risk. In addition,

\footnotetext{
${ }^{11}$ As a robustness check, we following Shu et al. (2012) and include (strategy $\times$ year) fixed effects in all regressions to control for any unobservable, omitted variables that are specific to each strategy and year, and find similar results.
} 
hedge funds with high water mark provisions, longer lockup periods, the use of leverage, and an annual audit tend to take more risk. Regarding the county-level demographic variables, we find that hedge funds located in counties with older population, lower education level, higher income, lower total population, higher male to female ratio, less minority population, and less married households appear more likely to take higher total or idiosyncratic risk.

In sum, the regression results show that hedge funds located in counties with higher religiosity ratios are more likely to undertake lower total and idiosyncratic risk, indicating that risk aversion induced by local religiosity may lead to lower risk-taking even in the highly competitive hedge fund industry.

\subsection{The relation between local religiosity and hedge fund risk-taking by investment strategy}

In this section we investigate whether our main findings change across various hedge fund investment strategies. Some funds are willing to take direct market exposure and risk (directional strategies), such as managed futures, global macro, and emerging market funds. Some diversify market risk by taking both long and short, diversified positions (semi-directional strategies), such as fund-of-funds, equity hedge, event-driven, and multi-strategy funds. Others aim to minimize market risk altogether (non-directional strategies), such as equity market neutral, fixed income arbitrage, and convertible arbitrage funds.

We divide our full sample into five subsamples based on the investment strategies provided by the HFR database: (1) equity hedge, (2) event-driven, (3) fund of funds, (4) macro, and (5) relative value, and perform subsample analysis. The equity hedge, event-driven, and fund of funds (strategies (1) through (3)) are semi-directional strategies that rank in the middle 
regarding risk level; macro (strategy (4)) is the directional strategy that involves the greatest risk; and relative value (strategy (5)) is the non-directional strategy that is the least aggressive.

In untabulated tests, we conduct portfolio analysis and examine the average excess risk measures across quintiles of religiosity ratio for different investment strategies. We find that after excluding the most and least aggressive strategies (i.e., excluding strategy (4) and (5)), the mean values of both fund excess Total Risk and Idiosyncratic Risk decrease with religiosity, and the result is stronger compared to the full sample result in Table 3. For instance, the difference between the highest and lowest religiosity quintiles is $-0.51 \%(t=-5.12)$ and $-0.26 \%(t=-5.24)$ for mean excess Total Risk and Idiosyncratic Risk, respectively. Overall, the portfolio result suggests that the negative relation between religiosity and hedge fund risk taking appears to be driven by the semi-directional strategies.

To ensure the robustness of the results, we also estimate fixed effects panel and FamaMacBeth regressions of hedge fund risk-taking on local religiosity $(R E L)$ by strategy. We include all control variables, but only report the coefficients on REL for brevity. For panel regressions, we include year fixed effects for each of the five strategies, and (strategy $\times$ year) fixed effects for semi-directional strategies (1), (2), and (3) altogether.

[Insert Table 5 about here]

Consistent with the portfolio analyses, the regression results in Table 5 show that the negative relation between local religiosity and hedge fund risk-taking appears to be primarily driven by semi-directional strategies (which account for about $70 \%$ of the sample), in particular equity hedge and event-driven funds. For the least aggressive non-directional strategy such as relative value, local religiosity does not appear to relate to hedge fund risk-taking, likely due to the small variation in risk levels for this least risky strategy. For the most aggressive directional 
strategy, macro, however, local religiosity is significantly positively related to fund risk-taking. This result is indeed consistent with Shu et al. (2012)'s finding that the more risky growth and aggressive growth equity mutual funds located in more religious counties tend to take more risk. Overall the evidence suggests that the difference between the results of our paper and Shu et al. (2012) could be attributed to fund styles. ${ }^{12}$

\subsection{Endogeneity}

Thus far, we have documented a significant negative relation between local religious beliefs and hedge fund risk-taking, particularly total and idiosyncratic return volatilities. While our results suggest a negative effect of local religiosity on hedge fund risk-taking, they are also consistent with two alternative explanations. First, this negative association may be due to reverse causality in the sense that more risk-averse managers tend to choose funds located in areas with more religious populations. In particular, local culture and religious beliefs may attract fund managers and employees who share the same cultural background, as individuals prefer to work and reside in areas having local culture and beliefs with which they feel comfortable (Schneider (1987)). For example, Hilary and Hui (2009) show that CEOs consistently choose to work for employers with the same local culture. Second, the negative association may be driven by other unobservable factors correlated with both local religiosity and hedge fund risk-taking.

To distinguish between these alternative explanations and establish causality, we have conducted various tests to control for potential endogeneity. For example, we use a variety of

\footnotetext{
${ }^{12}$ It is also worth noting that the results are indeed consistent with the local preference channel discussed later in Section 4. We will then discuss these results in more details.
} 
control variables in our regressions and include year and investment strategy fixed effects to control for unobservable, strategy-related, omitted variables. We now perform several tests to further control for potential endogeneity including IV regressions, dynamic panel GMM estimation, and a horse-race analysis between college- and fund-location religiosity.

\subsubsection{IV regressions}

Following prior literature such as Hilary and Hui (2009), we identify two instrumental variables for our endogenous variable $(R E L) .{ }^{13}$ The first instrument is the 3-year lagged religiosity (REL_lag3). To the extent that local religiosity remains stable over time, historical religiosity is expected to be positively related to current religiosity (the relevance criterion). However, there is no obvious reason as to why local religiosity three years ago would impact current risk-taking by hedge funds, other than through the effects of current religiosity (the exclusion criterion). The second instrument used is the total population of a hedge fund's local county lagged by three years, ttlpop_lag3 (Hilary and Hui (2009)). While historical county population is highly likely to be related to current religiosity ratio (the relevance criterion), the 3year lagged population should not have any impact on hedge fund risk-taking behaviors, other than through current religiosity (the exclusion criterion). Since we use two instruments for one endogenous variable, we are able to estimate an over-identified system and conduct various statistical tests for instrument validity.

In the first stage of IV regressions, we regress $R E L$ on the two instruments, along with various hedge fund characteristics and county-level demographic variables. In the second stage,

\footnotetext{
${ }^{13}$ We use an additional instrumental variable, i.e., the median age of the county population lagged by three years, in the IV regressions; the results are qualitatively similar.
} 
we regress various risk-taking measures on the fitted value of $R E L$ from the first stage estimation and all controls. We include both strategy and year fixed effects in all of our regressions. ${ }^{14}$

\section{[Insert Table 6 about here]}

Table 6 presents the IV regression results. The endogeneity tests suggest that $R E L$ is endogenous in predicting total and idiosyncratic risk ( $p$-value $=0.000$ in both cases). The first stage evidence shows that both instruments are significantly positively related to current $R E L$ satisfying the relevance criterion. The first stage F-test also indicates that the weak instrument problem is unlikely ( $p$-value $<0.0000$ ). The second stage $p$-value for Hansen J-statistic equals 0.7114 for total risk and 0.4935 for idiosyncratic risk. Therefore, our two instruments are jointly exogenous and valid.

More importantly, the second stage regression results show that REL is still significantly negatively related to total and idiosyncratic risk. Indeed, both the statistical significance and economic magnitude of the coefficient estimates on $R E L$ are greater than those for the baseline panel regressions. Overall the evidence suggests that local religiosity has a negative effect on hedge fund risk-taking behaviors, even after we address endogeneity concerns through instrumental variables regressions.

\subsubsection{Dynamic panel GMM estimations}

To further address the endogeneity problem, we follow Wintoki et al. (2012) and apply a dynamic panel GMM estimator in this section. Specifically, we estimate the following dynamic GMM model of Blundell and Bond (1998) using lagged risk measures as our instruments. ${ }^{15}$

\footnotetext{
${ }^{14}$ As robustness checks, we use a variety of alternative model specifications and fixed effects and our results remain unchanged.

${ }^{15}$ Results are similar when we use dependent variables lagged by multiple years as our instruments. For details on the dynamic panel GMM estimation and the Stata program used, see the Appendix of Wintoki et al. (2012). For
} 


$$
\text { HFRisk }_{i, t}=\alpha+\theta \text { HFRisk }_{i, t-1}+\beta R E L_{i, t}+\gamma X_{i, t}+\varepsilon_{i, t},
$$

where HFRisk $k_{i, t}$ is the total or idiosyncratic risk of hedge fund $i$ in year $t, R E L_{i, t}$ is the local religiosity ratio of fund $i$ in year $t$, and $X$ contains all control variables such as fund characteristics and demographic factors, as well as various fixed effects. The untabulated results show that the coefficients on $R E L$ are significantly negative for both total and idiosyncratic volatilities, and the economic magnitudes are indeed substantially enhanced relative to the other previously used methodologies. In sum, we document qualitatively similar results after controlling for endogeneity using dynamic panel GMM estimators.

\subsubsection{Hedge fund managers' college- vs. fund-location religiosity}

In this section, we further address endogeneity concerns arising from reverse causality by exploring the effects of fund managers' college- versus fund-location religiosity on their risktaking behaviors. Specifically, we conduct an extensive internet search for the biographies of hedge fund managers and hand collect the names of the undergraduate universities attended by fund managers for each of our sample hedge funds. ${ }^{16}$ We then add the county-level religiosity ratios of managers' college locations (College REL) to our regressions and conduct a horse-race analysis. College-location religiosity may capture fund managers' innate religious beliefs for at least two reasons (Shu et al. (2012)). First, it is likely that people with certain religious beliefs are drawn to a college which has a similar local culture and religion. Second, local religiosity at the college location may help nurture a person's religious beliefs during the college years.

studies using dynamic panel GMM estimation, see also Roodman (2009), Warr, Elliott, Koëter-Kant, and Öztekin (2012), and Flannery and Hankins (2013), among others.

${ }^{16}$ Similar to Shu et al. (2012), analyses of college location religiosity significantly reduce our sample size due to (1) missing information on undergraduate colleges attended by fund managers from internet search; and (2) fund managers attending non-U.S. undergraduate universities. 
We conjecture that if risk aversion induced by local religiosity leads to reduction in hedge fund risk-taking behaviors (the "local religiosity impact" hypothesis) then we expect to observe that local religiosity dominates managers' college-location religiosity. Alternatively, if our findings are driven by reverse causality, that is, managers with certain religious beliefs or greater risk aversion are attracted to counties with higher religiosity ratios (the "self-selection" hypothesis) then we expect to see stronger effects of managers' college-location religiosity on risk-taking as compared to fund-location religiosity.

To further distinguish between the "local religiosity impact" and "self-selection" hypotheses, we also focus on a subsample of fund managers whose undergraduate universities are located far enough from hedge fund locations, i.e., in different U.S. Census Bureau regions. ${ }^{17}$ Since it is unlikely that the religiosity ratios of a college location in different regions are significantly correlated with the characteristics associated with the fund's location (Shu et al. (2012)), we expect the differential effects between college- and fund-location religiosity to be more pronounced for this subsample than for the full sample where the two religiosity ratios might be the same for some observations.

\section{[Insert Table 7 about here]}

Table 7 reports multivariate regression results of total and idiosyncratic risk on managers' college-location religiosity ratios as well as a horse-race analysis between college- and fundlocation religiosity. Panel A uses the full sample where we can manually identify fund managers' undergraduate colleges in the U.S., and Panel B uses the subsample where managers' colleges are located in different U.S. Census Bureau regions than fund locations. Note that, for both the full- and sub-sample tests, we exclude the most risky, directional strategy (Macro) and the least

\footnotetext{
${ }^{17}$ The U.S. Census Bureau classifies the U.S. territory into four regions: Northeast, Midwest, South, and West. See detailed classifications at http://www2.census.gov/geo/docs/maps-data/maps/reg_div.txt.
} 
aggressive, non-directional strategy (Relative Value) to avoid the confounding effects from these two strategies as shown in Section 3.3. Namely, we only focus on hedge funds whose investment strategies belong to the semi-directional category: (1) Equity Hedge, (2) Event-Driven, and (3) Fund of Funds. In addition, we control for the demographic characteristics associated with both college and fund locations in all tests.

Panel A of Table 7 shows that the coefficients on College REL are significantly negative, suggesting that to the extent that College REL captures managers' innate religious beliefs, they do affect hedge fund risk-taking behaviors. After controlling for College REL, however, the coefficients on local religiosity $(R E L)$ remains significant and negative. Indeed, the coefficient magnitudes on REL are greater than those on College REL. Consistent with our main findings, Panel A suggests that even after controlling for reverse causality, local religiosity ratio has a significant negative impact on managers' risk-taking behaviors.

More importantly, Panel B of Table 7 shows that once we consider the subsample where the college location is in a different U.S. Census Bureau region than the fund's location, the coefficient estimates on College REL become only marginal for total risk and insignificant for idiosyncratic risk. On the contrary, after controlling for College REL, the coefficients on $R E L$ remain significant and negative, and have the same magnitude as those from the full sample regressions in Panel A.

Collectively, the horse-race analyses between college- and fund-location religiosity ratios lend further support to our hypothesis that local religious beliefs reduce hedge fund risk taking. While we do not rule out the possibility that more risk averse managers are drawn to counties with higher religiosity ratios, Table 7 provides support that our results are not simply driven by reverse causality. 


\subsection{Additional robustness tests}

In this section, we perform several additional robustness tests. First, we examine the effect of financial crises on our main findings. We also investigate whether our results are robust to the exclusion of hedge funds located in New York, which has the highest fund concentration.

\subsubsection{The effect of financial crises}

In this section, we examine the effect of local religiosity on hedge fund risk-taking during financial crisis versus non-crisis periods. Specifically, we refer to the years of 1998 (Asian financial crisis and LTCM), 2007, and 2008 (the most recent subprime mortgage crisis) as crisis period, and non-crisis period otherwise. Table 8 shows that while the coefficients on REL are significantly negative across both crisis and non-crisis periods, the effect appears to be larger for the crisis period. ${ }^{18}$ Overall the evidence suggests that the risk-reduction effect of $R E L$ is especially stronger and more valuable during crisis years, which are characterized by excessive risk-taking and uncertainty.

[Insert Table 8 about here]

\subsubsection{Excluding hedge funds located in New York}

We now examine whether our findings are robust to the exclusion of states that have the highest hedge fund concentrations. While the locations of our sample hedge funds distribute across 46 states in the U.S., the top three states of hedge fund concentration are New York (38\%), California (12.6\%), and Illinois (9.5\%). Altogether, these states constitute approximately

\footnotetext{
${ }^{18}$ Again, we only focus on semi-directional strategies in the regressions to mitigate potential confounding effects.
} 
$60 \%$ of the full sample. In light of the dominance of New York in hedge fund locations, we conduct robustness tests by excluding funds located in New York.

The untabulated tests suggest a robust negative relation between local religiosity and hedge fund total and idiosyncratic volatilities. To further ensure the robustness of our findings, we also exclude hedge funds located in the top two states and the top three states and find similar

results. This evidence suggests that the negative relation between local religiosity and hedge fund risk-taking is not driven by states that have the highest hedge fund concentrations.

\subsection{Local religious beliefs and hedge fund performance}

Thus far, we have shown that risk aversion induced by local religiosity leads to lower hedge fund risk-taking. The natural question therefore arises as to whether local religious beliefs subsequently affect hedge fund performance. To address this question, we use the Nine-Factor Alpha estimated from annual regressions of monthly fund returns on the Carhart (1997) and Fung and Hsieh (2004) combined nine factors as shown in Equation (1).

In untabulated tests, we estimate panel and Fama-MacBeth regressions of hedge fund performance as proxied by Nine-Factor Alphas on local religiosity. To control for potential endogeneity, we also run IV regressions and dynamic panel GMM estimation. Across all models, $R E L$ is insignificantly related to Alpha, suggesting that local religiosity does not affect hedge fund performance.

The overall evidence indicates that while local religiosity reduces hedge fund risk-taking, it does not (negatively) impact fund performance. Therefore, the higher return volatilities of hedge funds located in counties with lower religiosity ratios are not rewarded by higher returns. This finding has important implications for investors, fund managers, and policy makers alike. 


\subsection{Across religious groups: Catholic vs. Protestant}

It is worth noting that Shu et al. (2012) focus on the effect of different religious beliefs, i.e., Catholicism vs. Protestantism, on mutual fund risk-taking. In this paper, we instead focus on the effect of the level of local religiosity on hedge fund risk-taking because prior literature has established a robust association between religious beliefs and individuals' risk aversion. However, the literature is inconclusive regarding the differences across religious groups.

On the one hand, several studies suggest that Catholics may exhibit less aversion to speculative risk than average population, whereas Protestants exhibit more aversion to speculative risk (Halek and Eisenhauer (2001)). This distinction may reflect differences in religious teachings regarding gambling in general: while Protestant philosophy strongly condemns any kind of gambling activity and considers it sinful, Catholic philosophy is somewhat tolerant of gambling and Catholic churches even use bingo and lottery for their own fundraising (Halek and Eisenhauer (2001) and Adhikari and Agrawal (2016a)). Indeed, Kumar (2009) and Kumar et al. (2011) show that both individual and institutional investors in predominantly Catholic (Protestant) locations invest more (less) in lottery-type stocks. Shu et al. (2012) show that mutual finds located in counties with high Catholics to Protestants ratio (CP-Ratio) tend to undertake higher risk. Adhikari and Agrawal (2016a) show that firms headquartered in counties with higher CP-Ratio tend to be more innovative.

On the other hand, Stulz and Williamson (2003) suggest that Protestants tend to be more risk-tolerant than Catholics. Similarly, Baxamusa and Jalal (2015) find that CEOs who selfidentify as Catholics are inclined to undertake less risk. 
In contrast to both of the above views, Hilary and Hui (2009) show that non-financial firms headquartered in counties with high Catholic or Protestant ratios take less risk. Likewise, Adhikari and Agrawal (2016b) document that a large Catholic or Protestant population in an area negatively predicts bank risk-taking, although the latter result is weaker.

Given this ambiguity in literature, we focus on the level of local religiosity in this paper. Nevertheless, for completeness we also consider the CP-Ratio as well as the separate Catholic and Protestant ratios as measures of local religious beliefs, and find mixed results. Specifically, both the CP-Ratio and Catholic ratio are negatively related to hedge fund risk, while the Protestant ratio is either positively or insignificantly related to fund risk. And the results are primarily driven by semi-directional strategies.

\section{Local Preference Channel: Risk Preferences of Local Managers and Investors}

So far we have documented that hedge funds located in more religious counties tend to take less risk. In this section, we investigate the underlying channel through which local religiosity could negatively affect hedge fund risk-taking behaviors, namely, the effect of local religiosity on the risk aversion of local hedge fund managers and investors.

Arguably, the risk preferences of local managers and investors could play an important role in determining the impact of local religiosity on hedge fund risk-taking. For instance, hedge fund managers are often local or conform to local cultural and religious forms, and they care greatly about hedge fund idiosyncratic risk because they are often under-diversified and their human capital, compensation, and total wealth are disproportionately tied to the fund that they manage. In addition, the literature on local bias suggests that hedge funds tend to hold more local stocks in their portfolios (Teo (2009)), which makes fund idiosyncratic risk important for them. 
Moreover, hedge fund managers are hired to act in the best interest of their investors and can benefit from catering to local investors' risk preferences (Sialm et al. (2014)). In sum, higher local religiosity could induce higher risk aversion of local managers and investors, thus leading to lower hedge fund risk-taking. This argument implies that if the risk preferences of local managers and investors present one mechanism by which local religiosity affects hedge fund risk-taking, we expect to find a more pronounced effect of local religiosity on risk-taking in subsamples of hedge funds for which local managers and investors are economically more important.

To test the local preference channel, we consider three indicators of the importance of local managers and investors: hedge fund strategy, age, and size. In particular, Sialm et al. (2014) suggest that semi-directional strategies such as equity hedge and event studies are most likely to be affected whereas directional strategies such as macro are least likely to be impacted by local investor preferences. In addition, younger and smaller funds are more dependent upon and thus affected by local managers and investors compared to older and larger funds. For instance, local investors' preferences are perhaps less important to old and large hedge funds, which are highly visible and have large and disperse investor bases. Moreover, as Yonker (2016) implies, young and small hedge funds are more likely to have local residents in the top management team. Therefore, we expect to see stronger effects of local religiosity on risk-taking in semi-directional rather than directional strategies, young rather than old, and small rather than large funds.

As mentioned earlier, the results in Table 5 are indeed consistent with our conjecture regarding hedge funds strategies. We find that local religiosity is significantly negatively related to risk-taking for semi-directional strategies, but positively related to risk-taking for directional strategies, indicating that the negative effect of local religiosity on hedge fund risk-taking may be 
at least partially driven by local preferences.

[Insert Table 9 about here]

Panel A of Table 9 compares young versus old hedge funds, where young funds are defined as those aged below the sample median (i.e., 5 years for our sample) and old funds those above. We show that the negative relation between local religiosity and hedge fund risk-taking is only significant for young funds but nonexistent for old funds. This result is consistent with local preference hypothesis, to the extent that young and new funds rather than old and established ones depend more on local managers and investors and in turn are more affected by local residents' risk preferences.

Panel B of Table 9 compares small and large funds, where small ones are those with AUMs below the sample median and large ones otherwise. Again, consistent with the local preference channel, we find that the negative effect of local religiosity on hedge fund risk-taking is only significant for small funds but insignificant for large funds.

Overall, the subsample regression results show that the inverse relation between local religiosity and hedge fund risk-taking is primarily driven by funds more likely to cater to local risk preferences, namely young and small funds. These analyses, combined with the earlier findings on hedge fund strategies suggest that risk preferences of local managers and investors constitute one channel through which local religiosity mitigates hedge fund risk-taking.

\section{Local Religiosity and Hedge Fund Holdings}

In this section we examine hedge fund stock holdings to investigate whether hedge funds located in more religious counties tend to take lower risk by investing in less risky stocks and diversify risk at the portfolio level. 
We obtain holdings from Thomson Reuters institutional holdings (13F) database, which reports quarterly U.S. equity positions of all institutions (including hedge fund firms) with more than $\$ 100$ million of AUM. We match each hedge fund in our main sample with the $13 \mathrm{~F}$ database by name and identify 1,637 hedge fund firms. Since 13F dataset does not cover the short positions or derivatives, we only focus on the long equity positions of hedge fund firms. We then estimate various holdings-based risk measures for each hedge fund firm following Shu et al. (2012).

\section{[Insert Table 10 about here]}

First, we investigate whether hedge funds located in counties with higher religiosity ratios tend to reduce risk-taking by holding individual stocks with lower return volatilities. To answer this question, each year we estimate total and idiosyncratic risk for each stock with at least 18 months of return observations on a 24-month rolling window basis as the standard deviation of monthly returns and the residuals from the Carhart (1997) four-factor model, respectively. We then calculate value-weighted averages of total and idiosyncratic risk of individual stocks held by each hedge fund. Panel A of Table 10 shows that local religiosity is significantly negatively related to average total and idiosyncratic return volatilities of stocks held by hedge funds. Our results suggest that higher local religiosity ratios reduce hedge fund managers' risk-taking at the individual stock level, i.e., through holding less risky stocks.

We next examine whether the differences in hedge fund risk-taking behaviors across counties with varying local religiosity ratios are also attributed to portfolio diversification. To explore this channel, we examine total and idiosyncratic return volatilities of hypothetical holdings-based hedge fund portfolios. Specifically, we first calculate holdings-based portfolio returns as the monthly buy-and-hold returns of hedge funds' reported equity holdings on a value- 
weighted basis. We then estimate portfolio total and idiosyncratic risk, respectively, as the standard deviation of hypothetical fund portfolio monthly returns and the residuals from the Carhart (1997) four-factor model on a 24-month rolling window basis every year. Panel B of Table 10 shows that local religiosity is significantly and negatively related to portfolio total and idiosyncratic risk, suggesting that local religiosity not only reduces hedge fund managers' incentives to hold riskier individual stocks but also increases fund portfolio diversification.

Finally, to shed further light on portfolio diversification, we directly investigate two metrics of industry concentration of hedge fund portfolios: (1) Industry Herfindahl Index, defined as the sum of squared industry weights of a hedge fund portfolio; and (2) KSZ Index, i.e., Kacperczyk, Sialm, and Zheng (2005) industry concentration index, defined as the sum of squared differences between a fund portfolio's industry weights and the corresponding market's industry weights. Panel $\mathrm{C}$ of Table 10 documents that local religiosity is significantly negatively related to both concentration measures, suggesting that hedge funds located in lower religiosity ratio areas tend to deviate from well-diversified portfolios and concentrate in fewer industries.

Overall, the results suggest that hedge funds located in counties with higher religiosity ratios tend to not only hold individual stocks with lower return volatilities, but also diversify their portfolios across industries, thus contributing to lower hedge fund risk-taking.

In contrast to our findings, Shu et al. (2012) document that local religiosity only appears to affect mutual fund risk-taking at the portfolio level, but not at the individual stock level. One potential explanation for this difference is that whereas mutual funds experience closer scrutiny and thus are less willing to take risk on individual stocks that may be observable to competitors and clients, hedge funds are lightly regulated and subject to less scrutiny, and hence tend to undertake risk at the individual stock level as well as the portfolio level. Further, while Shu et al. 
(2012) suggest that their results cannot be attributed to mutual fund managers' local stock preference, it is possible that our results are driven by hedge fund managers located in more religious counties investing disproportionally in less risky local stocks (Teo (2009)).

\section{Conclusions}

In this paper, we examine the effect of local religious beliefs on organizational risktaking using hedge funds as a new and unique setting. While prior literature suggests that local religiosity induced risk aversion may mitigate hedge fund risk-taking, the unique features of hedge funds (e.g., stiff competition and heightened financial incentives) may make it least likely for religion to affect hedge fund risk-taking behaviors. Thus, if we document significant evidence in the hedge fund industry, it would provide strong support for the impact of local religiosity on organizational risk-taking.

Using a sample of 7,033 hedge funds from the HFR database and county-level religiosity data during 1996-2013, we document robust evidence that local religiosity is significantly negatively related to total and idiosyncratic risk of hedge funds. This relation still holds even after controlling for endogeneity using IV regressions, dynamic panel GMM estimations, and a horse-race analysis between managers' college- and fund-location religiosity, indicating that local religious beliefs instill a risk-aversion culture to the hedge fund industry. Further, we find that the risk mitigating effect of local religiosity exists for both crisis and non-crisis periods but appears to be stronger during crisis period, when it is most important and needed, i.e., during time periods with excessive risk-taking and uncertainty. The result is also robust to excluding hedge funds in the state with the highest hedge fund concentration. However, we do not find local religiosity affects hedge fund performance. 
We next investigate the underlying channel through which local religiosity mitigates hedge fund risk-taking. The evidence shows that the effect of local religiosity on the risk preferences of local managers and investors may, at least partially, help explain our finding. Specifically, we find that the negative relation between local religiosity and hedge fund risktaking is only pronounced among funds for which local managers and investors are economically more important, i.e., semi-directional (such as equity hedge) rather than directional (such as macro), young rather than old, and small rather than large funds.

Finally, analyses of hedge fund equity holdings show that funds located in counties with higher religiosity ratios tend to hold less risky stocks and diversify their stock portfolios across industries, thus contributing to lower hedge fund return volatilities.

Taken together, our evidence shows that local religious beliefs, an important component of local culture, may motivate hedge fund managers to reduce risk-taking. These findings could further our understanding of the effect of local religiosity on organizational risk-taking behaviors in the financial industry in general and the hedge fund sector in particular. Our study also provides important insights into hedge fund managers' risk-taking incentives. Further, our results have important implications for investors and policymakers alike, especially those who are concerned about the risk-taking behaviors of hedge funds and their impact on the whole economy. In particular, a potential policy implication is that any regulatory tools aimed at preventing hedge funds from taking excessive risks should also take into account differences in inherent culture-driven risk-taking preferences of hedge funds' key stakeholders. 


\section{References}

Adhikari, Binay Kumar, and Anup Agrawal, 2016a, Religion, gambling attitudes and corporate innovation, Journal of Corporate Finance 37, 229-248.

Adhikari, Binay Kumar, and Anup Agrawal, 2016b, Does local religiosity matter for bank risktaking?, Journal of Corporate Finance 38, 272-293.

Aggarwal, Rajesh K., and Philippe Jorion, 2010, The performance of emerging hedge funds and managers, Journal of Financial Economics 96, 238-256.

Alesina, Alberto, and Elliana La Ferrara, 2000, Participation in heterogeneous communities, Quarterly Journal of Economics 115, 847-904.

Aragon, George O., and Vikram Nanda, 2012, Tournament behavior in hedge funds: High water marks, fund liquidation, and managerial stake, Review of Financial Studies 25, 937-974.

Bainbridge, William Sims, 1989, The religious ecology of deviance, American Sociological Review 54, 288-295.

Bali, Turan G., Stephen J. Brown, and Mustafa O. Caglayan, 2011, Do hedge funds' exposures to risk factors predict their future returns?, Journal of Financial Economics 101, 36-68.

Baxamusa, Mufaddal, and Abu Jalal, 2015, CEO's religious affiliation and managerial conservatism, Financial Management 45, 67-104.

Blundell, Richard, and Stephen Bond, 1998, Initial conditions and moment restrictions in dynamic panel data models, Journal of Econometrics 87, 115-143.

Boone, Jeff P., Inder K. Khurana, and K. K. Raman, 2013, Religiosity and tax avoidance, Journal of American Taxation Association 35, 53-84.

Brown, Stephen J., William N. Goetzmann, and James Park, 2001, Careers and survival: Competition and risks in the hedge fund and CTA industry, Journal of Finance 56, 18691886.

Callen, Jeffrey L., and Xiaohua Fang, 2015, Religion and stock price crash risk, Journal of Financial and Quantitative Analysis 50, 169-195.

Carhart, Mark M., 1997, On persistence in mutual fund performance, Journal of Finance 52, 5782.

Chen, Yong, 2011, Derivatives use and risk taking: Evidence from the hedge fund industry, Journal of Financial and Quantitative Analysis 46, 1073-1106.

Cochran, John K., and Ronald L. Akers, 1989, Beyond hellfire: An exploration of the variable effects of religiosity on adolescent marijuana and alcohol use, Journal of Research in Crime and Delinquency 26, 198-225.

Coval, Joshua D., and Tobias J. Moskowitz, 1999, Home bias at home: Local equity preference in domestic portfolios, Journal of Finance 54, 2045-2073.

Coval, Joshua D., and Tobias J. Moskowitz, 2001, The geography of investment: Informed trading and asset prices, Journal of Political Economy 109, 811-841.

Dyreng, Scott D., William J. Mayew, and Christopher D. Williams, 2012, Religious social norms and corporate financial reporting, Journal of Business Finance \& Accounting 39, 845875.

Evans, T. David, Francis T. Cullen, R. Gregory Dunaway, and Velmer S. Burton JR., 1995, Religion and crime reexamined: The impact of religion, secular controls, and social ecology on adult criminality, Criminology 33, 195-224.

Fama, Eugene F., and James D. MacBeth, 1973, Risk, return, and equilibrium: Empirical tests, Journal of Political Economy 81, 607-636. 
Flannery, Mark J., and Kristine Watson Hankins, 2013, Estimating dynamic panel models in corporate finance, Journal of Corporate Finance 19, 1-19.

Fung, William, and David A. Hsieh, 1997, Empirical characteristics of dynamic trading strategies: The case of hedge funds, Review of Financial Studies 10, 275-302.

Fung, William, and David A. Hsieh, 2000, Performance characteristics of hedge funds and commodity funds: Natural vs. Spurious biases, Journal of Financial \& Quantitative Analysis 35, 291-307.

Fung, William, and David A. Hsieh, 2001, The risk in hedge fund strategies: Theory and evidence from trend followers, Review of Financial Studies 14, 313-341.

Fung, William, and David A. Hsieh, 2004, Hedge fund benchmarks: A risk-based approach, Financial Analysts Journal 60, 65-81.

Grullon, Gustavo, George Kanatas, and James Weston, 2009, Religion and corporate (mis)behavior, Working paper, Rice University.

Guiso, Luigi, Paola Sapienza, and Luigi Zingales, 2003, People's opium? Religion and economic attitudes, Journal of Monetary Economics 50, 225-282.

Halek, Martin, and Joseph G. Eisenhauer, 2001, Demography of risk aversion, Journal of Risk and Insurance 68, 1-24.

Heaton, Tim B., and Edith L. Pratt, 1990, The effects of religious homogamy on marital satisfaction and stability, Journal of Family Issues 11, 191-207.

Hilary, Gilles, and Kai Wai Hui, 2009, Does religion matter in corporate decision making in America?, Journal of Financial Economics 93, 455-473.

Hogg, Michael, and Dominic Abrams, 1988. Social identifications: A social psychology of intergroup relations and group processes. (Routledge).

Iannaccone, Laurence R., 1998, Introduction to the economics of religion, Journal of Economic Literature 36, 1465-1495.

Kacperczyk, Marcin, Clemens Sialm, and Lu Zheng, 2005, On the industry concentration of actively managed equity mutual funds, Journal of Finance 60, 1983-2011.

Kumar, Alok, 2009, Who gambles in the stock market?, Journal of Finance 64, 1889-1933.

Kumar, Alok, Jeremy K. Page, and Oliver G. Spalt, 2011, Religious beliefs, gambling attitudes, and financial market outcomes., Journal of Financial Economics 102, 671-708.

La Porta, Rafael, Florencio Lopez-de-Silanes, Andrei Shleifer, and Robert Vishny, 1999, The quality of government, Journal of Law, Economics and Organization 15, 222-279.

Lehrer, Evelyn L., and Carmel U. Chiswick, 1993, Religion as a determinant of marital stability, Demography 30, 385-404.

Lo, Andrew W., 2008, Hedge funds, systemic risk and the financial crisis of 2007-2008: Written testimony for the House Oversight Committee hearing on hedge funds, Massachusetts Institute of Technology.

McGuire, Sean T., Thomas C. Omer, and Nathan Y. Sharp, 2012, The impact of religion on financial reporting irregularities, The Accounting Review 87, 645-673.

Osoba, Brian J., 2003, Risk preferences and the practice of religion: Evidence from panel data, Working paper, West Virginia University.

Roodman, David, 2009, How to do xtabond2: An introduction to difference and system GMM in Stata, The Stata Journal 9, 86-136.

Schneider, Benjamin, 1987, The people make the place, Personnel Psychology 40, 437-453.

Shu, Tao, Johan Sulaeman, and P. Eric Yeung, 2012, Local religious beliefs and mutual fund risk-taking behaviors, Management Science 58, 1779-1796 
Sialm, Clemens, Zheng Sun, and Lu Zheng, 2014, Home bias and local contagion: Evidence from funds of hedge funds, working paper, University of Texas at Austin and University of California, Irvine.

Smith, David M., Na Wang, Ying Wang, and Edward J. Zychowicz, 2016, Sentiment and the Effectiveness of Technical Analysis: Evidence from the Hedge Fund Industry, Journal of Financial and Quantitative Analysis, forthcoming.

Stulz, René M., and Rohan Williamson, 2003, Culture, openness, and finance, Journal of Financial Economics 70, 313-349.

Tajfel, Henry, ed., 1978. Differentiation between social groups: Studies in the social psychology of intergroup relations (Academic Press).

Teo, Melvyn, 2009, The geography of hedge funds, Review of Financial Studies 22, 3531-3561.

Teo, Melvyn, 2011, The liquidity risk of liquid hedge funds, Journal of Financial Economics $100,24-44$.

Warr, Richard S., William B. Elliott, Johanna Koëter-Kant, and Özde Öztekin, 2012, Equity mispricing and leverage adjustment costs, Journal of Financial and Quantitative Analysis 47, 589-616.

Wintoki, M. Babajide, James S. Linck, and Jeffry M. Netter, 2012, Endogeneity and the dynamics of internal corporate governance, Journal of Financial Economics 105, 581606.

Yonker, Scott E., 2016, Geography and the market for CEOs, Management Science, forthcoming. 


\section{Appendix A. Variable Definitions}

\begin{tabular}{|c|c|}
\hline Variables & Definitions \\
\hline \multicolumn{2}{|c|}{ Hedge fund risk-taking measures: } \\
\hline Total Risk & $\begin{array}{l}\text { Standard deviation of monthly returns of each hedge fund on a } 24- \\
\text { month rolling window. }\end{array}$ \\
\hline Idiosyncratic Risk & $\begin{array}{l}\text { Standard deviation of the residuals from the nine-factor model, in which } \\
\text { we combine the Carhart (1997) four factors and Fung and Hsieh (2004) } \\
\text { seven factors. }\end{array}$ \\
\hline Average Total Risk & $\begin{array}{l}\text { Value-weighted average total risk of stocks held by each hedge fund. } \\
\text { Each year, we estimate total risk as the standard deviation of monthly } \\
\text { returns on a } 24 \text {-month rolling window basis for each stock with at least } \\
18 \text { months of return observations. }\end{array}$ \\
\hline Average Idiosyncratic Risk & $\begin{array}{l}\text { Value-weighted average idiosyncratic risk of stocks held by each hedge } \\
\text { fund. Each year, we estimate idiosyncratic risk as the standard deviation } \\
\text { of the residuals from the Carhart (1997) four-factor model on a } 24- \\
\text { month rolling window basis for each stock with at least } 18 \text { months of } \\
\text { return observations. }\end{array}$ \\
\hline Nine-Factor Alpha & $\begin{array}{l}\text { The intercept from the annual regressions of monthly hedge fund } \\
\text { returns on the combined Carhart (1997) and Fung and Hsieh (2004) } \\
\text { nine factors. }\end{array}$ \\
\hline $\begin{array}{l}\text { Holdings-based Portfolio Total } \\
\text { Risk }\end{array}$ & $\begin{array}{l}\text { We first calculate holdings-based portfolio returns as the monthly buy- } \\
\text { and-hold returns of hedge funds' reported equity holdings, and then } \\
\text { estimate total risk as the standard deviation of holdings-based returns of } \\
\text { a hedge fund firm on a 24-month rolling window basis. }\end{array}$ \\
\hline $\begin{array}{l}\text { Holdings-based Portfolio } \\
\text { Idiosyncratic Risk }\end{array}$ & $\begin{array}{l}\text { We first calculate holdings-based portfolio returns as the monthly buy- } \\
\text { and-hold returns of hedge funds' reported equity holdings, and then } \\
\text { estimate idiosyncratic risk as the standard deviation of the residuals of } \\
\text { holdings-based returns of a hedge fund firm from the Carhart (1997) } \\
\text { four-factor model on a 24-month rolling window basis. }\end{array}$ \\
\hline Industry Herfindahl Index & $\begin{array}{l}\text { The sum of squared industry (four-digit SIC code) weights of a hedge } \\
\text { fund firm. }\end{array}$ \\
\hline KSZ Index & $\begin{array}{l}\text { Kacperczyk et al. (2005) industry concentration index, defined as the } \\
\text { sum of squared differences between a hedge fund firm's industry (four- } \\
\text { digit SIC code) weights and the corresponding market's industry } \\
\text { weights. }\end{array}$ \\
\hline
\end{tabular}

Local religiosity measures: REL

College REL

The religiosity ratio of the county where a fund is located, calculated as the total number of adherents of all congregations divided by the total population in the county.

The religiosity ratio of the county where a fund manager's undergraduate college is located, defined as the total number of adherents of all congregations divided by total population in the county.

\section{Hedge fund characteristics:}

leverage

high_watermark

fund_assets

Specifies whether a hedge fund intends to use leverage.

Specifies whether fees are taken only after a high watermark.

Total assets under management by the hedge fund. We take the natural logarithm in regressions ( $\log$ _fund_assets). 


$\begin{array}{ll}\text { firm_assets } & \text { Total assets under management by the hedge fund firm. We take the } \\ \text { natural logarithm in regressions (log_firm_assets). } \\ \text { Lockup interval (the number of months that new investor cannot } \\ \text { rodeem assets). } \\ \text { Indicates advance notice (in days) required for redemptions. } \\ \text { advance_notice } & \text { Annual management fee (in percentage). } \\ \text { management_fee } & \text { Minimum investment for the hedge fund. We take the natural logarithm } \\ \text { minimum_investment } & \text { in regressions (log_minimum_investment). } \\ \text { incentive_fee } & \text { Annual incentive fee (in percentage). } \\ \text { hurdle_rate } & \text { Specifies whether a hurdle rate exists. } \\ \text { audit } & \text { Indicates whether an annual audit is performed. } \\ & \\ \text { Local demographic characteristics: } & \text { The median age of the county population. } \\ \text { age } & \text { The fraction of advanced education attained. Educational attainment is } \\ \text { edu } & \text { defined by the percentage of people } 25 \text { years and above who have a } \\ & \text { Bachelor's, postgraduate, or professional degree. } \\ \text { income } & \text { The mean per capita personal income of a county. } \\ \text { Ttlpop } & \text { Total county population. We take the natural logarithm in regressions } \\ \text { (log_ttlpop). } & \text { The ratio of male to female population in the county. } \\ \text { mf } & \text { The fraction of the minority population in the total county population. } \\ \text { minority } & \text { The fraction of married households in the total number of households. } \\ \text { married } & \end{array}$


Table 1. Summary Statistics

This table provides summary statistics of key variables for our full sample during 1996-2013. All of the variables are defined in Appendix A and winsorized at the upper and lower 1\% levels.

\begin{tabular}{|c|c|c|c|c|c|c|c|c|}
\hline Variable & $\mathrm{N}$ & Mean & Std. Dev. & P25 & Median & P75 & Min & Max \\
\hline \multicolumn{9}{|c|}{ Panel A. Hedge Fund Risk Measures } \\
\hline Total Risk & 31,821 & 0.03 & 0.03 & 0.01 & 0.03 & 0.04 & 0.00 & 0.16 \\
\hline Idiosyncratic Risk & 31,821 & 0.01 & 0.02 & 0.00 & 0.01 & 0.02 & 0.00 & 0.08 \\
\hline \multicolumn{9}{|c|}{ Panel B. Hedge Fund Characteristics } \\
\hline leverage & 32,391 & 0.58 & 0.49 & 0.00 & 1.00 & 1.00 & 0.00 & 1.00 \\
\hline high_watermark & 32,391 & 0.87 & 0.33 & 1.00 & 1.00 & 1.00 & 0.00 & 1.00 \\
\hline fund_assets (\$mn) & 29,617 & 157.52 & 367.00 & 10.55 & 37.07 & 120.60 & 0.25 & 2515.51 \\
\hline firm_assets (\$mn) & 31,675 & 9,960 & 40,500 & 65.70 & 353 & 2,250 & 0.49 & 326,000 \\
\hline lockup & 31,058 & 4.65 & 6.88 & 0.00 & 0.00 & 12.00 & 0.00 & 84.00 \\
\hline advance_notice & 31,190 & 43.34 & 28.42 & 30.00 & 30.00 & 60.00 & 0.00 & 365.00 \\
\hline management_fee & 32,174 & 1.44 & 0.60 & 1.00 & 1.50 & 2.00 & 0.00 & 20.00 \\
\hline minimum_investment $(\$ \mathrm{mn})$ & 32,097 & 1.30 & 3.52 & 0.25 & 1.00 & 1.00 & 0.00 & 100.00 \\
\hline incentive_fee & 32,056 & 16.89 & 6.91 & 15.00 & 20.00 & 20.00 & 0.00 & 65.00 \\
\hline hurdle_rate & 32,391 & 0.13 & 0.34 & 0.00 & 0.00 & 0.00 & 0.00 & 1.00 \\
\hline audit ${ }^{-}$ & 32,391 & 0.92 & 0.28 & 1.00 & 1.00 & 1.00 & 0.00 & 1.00 \\
\hline \multicolumn{9}{|c|}{ Panel C. Local Religiosity } \\
\hline REL & 32,090 & 0.54 & 0.11 & 0.44 & 0.55 & 0.62 & 0.26 & 0.74 \\
\hline \multicolumn{9}{|c|}{ Panel D. Demographic Characteristics } \\
\hline age & 32,263 & 36.44 & 2.96 & 34.96 & 36.19 & 37.50 & 31.30 & 50.97 \\
\hline edu & 32,263 & 42.63 & 11.35 & 32.44 & 43.66 & 53.75 & 16.79 & 58.10 \\
\hline income & 32,074 & $58,953.00$ & $15,212.69$ & $46,503.50$ & $63,188.00$ & $70,883.00$ & $25,239.00$ & $86,010.50$ \\
\hline ttlpop $(000)$ & 32,263 & $1,870.00$ & $2,010.00$ & 805.00 & $1,540.00$ & $1,590.00$ & 0.09 & $9,820.00$ \\
\hline $\mathrm{mf}$ & 32,263 & 0.92 & 0.05 & 0.88 & 0.92 & 0.95 & 0.86 & 1.07 \\
\hline minority & 31,978 & 0.38 & 0.11 & 0.27 & 0.43 & 0.44 & 0.09 & 0.61 \\
\hline married & 31,978 & 0.16 & 0.03 & 0.12 & 0.15 & 0.19 & 0.11 & 0.23 \\
\hline
\end{tabular}




\section{Table 2. Correlation Coefficients}

This table reports the correlation coefficients among the key variables for our full sample during 1996-2013. All of the variables are defined in Appendix A and winsorized at the upper and lower $1 \%$ levels. ${ }^{*}$ indicates significance levels at $5 \%$ or better.

\begin{tabular}{|c|c|c|c|c|c|c|c|c|c|c|c|c|c|c|c|c|c|c|c|c|}
\hline & (1) & (2) & (3) & (4) & (5) & (6) & (7) & (8) & (9) & (10) & (11) & (12) & (13) & (14) & (15) & (16) & (17) & (18) & (19) & (20) \\
\hline (1) Total Risk & 1.00 & & & & & & & & & & & & & & & & & & & \\
\hline (2) Idio. Risk & $0.73^{*}$ & 1.00 & & & & & & & & & & & & & & & & & & \\
\hline (3) REL & $-0.02^{*}$ & $-0.04^{*}$ & 1.00 & & & & & & & & & & & & & & & & & \\
\hline (4) $\log _{-}$fund_assets & $-0.23^{*}$ & $-0.14^{*}$ & 0.01 & 1.00 & & & & & & & & & & & & & & & & \\
\hline (5) $\log _{-}$firm_assets & $-0.21^{*}$ & $-0.17^{*}$ & $0.04^{*}$ & $0.53^{*}$ & 1.00 & & & & & & & & & & & & & & & \\
\hline (6) advance_notice & $-0.15^{*}$ & $-0.14^{*}$ & $-0.03^{*}$ & $0.19^{*}$ & $0.09^{*}$ & 1.00 & & & & & & & & & & & & & & \\
\hline (7) $\log \_$min_invest & $-0.15^{*}$ & $-0.12^{*}$ & $0.01^{*}$ & $0.28^{*}$ & $0.22^{*}$ & $0.14^{*}$ & 1.00 & & & & & & & & & & & & & \\
\hline (8) management_fee & $0.09^{*}$ & $0.12^{*}$ & 0.00 & $0.00^{*}$ & $-0.05^{*}$ & $-0.12^{*}$ & -0.01 & 1.00 & & & & & & & & & & & & \\
\hline (9) incentive_fee & $0.16^{*}$ & $0.18^{*}$ & -0.02 & $-0.09^{*}$ & $-0.15^{*}$ & $-0.22^{*}$ & $0.06^{*}$ & $0.17^{*}$ & 1.00 & & & & & & & & & & & \\
\hline (10) high_watermark & $0.08^{*}$ & $0.09^{*}$ & $-0.04^{*}$ & -0.02 & $-0.06^{*}$ & $-0.03^{*}$ & $0.07^{*}$ & $0.04^{*}$ & $0.47^{*}$ & 1.00 & & & & & & & & & & \\
\hline (11) lockup & $0.06^{*}$ & $0.03^{*}$ & $-0.08^{*}$ & 0.00 & $-0.06^{*}$ & $0.31^{*}$ & $0.09^{*}$ & $-0.11^{*}$ & $0.02^{*}$ & $0.08^{*}$ & 1.00 & & & & & & & & & \\
\hline (12) hurdle_rate & $-0.07^{*}$ & $-0.06^{*}$ & $0.04^{*}$ & $0.03^{*}$ & $0.09^{*}$ & $0.06^{*}$ & $0.05^{*}$ & $-0.19^{*}$ & $-0.05^{*}$ & -0.02 & $0.03^{*}$ & 1.00 & & & & & & & & \\
\hline (13) leverage & $0.13^{*}$ & $0.13^{*}$ & $0.01^{*}$ & $-0.04^{*}$ & $-0.08^{*}$ & $-0.14^{*}$ & $-0.03^{*}$ & $0.10^{*}$ & $0.29^{*}$ & $0.13^{*}$ & $-0.02^{*}$ & $-0.08^{*}$ & 1.00 & & & & & & & \\
\hline (14) audit & $-0.03^{*}$ & $-0.01^{*}$ & $0.01^{*}$ & $0.09^{*}$ & $0.09^{*}$ & $0.10^{*}$ & $0.03^{*}$ & $-0.02^{*}$ & -0.01 & $0.06^{*}$ & $0.07^{*}$ & $0.01^{*}$ & $-0.03^{*}$ & 1.00 & & & & & & \\
\hline (15) age & $0.04^{*}$ & $0.06^{*}$ & $-0.09^{*}$ & 0.00 & $-0.10^{*}$ & 0.01 & $-0.04^{*}$ & $0.03^{*}$ & $-0.01^{*}$ & $-0.02^{*}$ & $-0.01^{*}$ & $-0.04^{*}$ & 0.00 & $-0.02^{*}$ & 1.00 & & & & & \\
\hline (16) edu & $-0.04^{*}$ & -0.01 & $-0.14^{*}$ & $0.18^{*}$ & $0.15^{*}$ & $0.12^{*}$ & $0.08^{*}$ & 0.01 & 0.01 & $0.05^{*}$ & $0.05^{*}$ & $-0.03^{*}$ & $0.05^{*}$ & $0.03^{*}$ & $0.15^{*}$ & 1.00 & & & & \\
\hline (17) income & $-0.03^{*}$ & $0.01^{*}$ & $0.17^{*}$ & $0.13^{*}$ & $0.09^{*}$ & $0.10^{*}$ & $0.04^{*}$ & $0.04^{*}$ & $0.00^{*}$ & $0.02^{*}$ & $0.02^{*}$ & $-0.03^{*}$ & $0.05^{*}$ & $0.01^{*}$ & $0.37^{*}$ & $0.75^{*}$ & 1.00 & & & \\
\hline (18) $\log _{\text {_ttlpop }}$ & $-0.08^{*}$ & $-0.07^{*}$ & $0.10^{*}$ & $0.05^{*}$ & $0.09^{*}$ & $0.03^{*}$ & $0.08^{*}$ & $0.06^{*}$ & $0.01^{*}$ & $0.03^{*}$ & -0.02 & 0.03 & $-0.09^{*}$ & $0.06^{*}$ & -0.34 & $-0.08^{*}$ & $-0.09^{*}$ & 1.00 & & \\
\hline (19) $\mathrm{mf}^{-1}$ & $0.08^{*}$ & $0.06^{*}$ & $-0.22^{*}$ & $-0.18^{*}$ & $-0.19^{*}$ & $-0.08^{*}$ & $-0.09^{*}$ & $-0.07^{*}$ & $0.04^{*}$ & $-0.01^{*}$ & $0.05^{*}$ & -0.02 & 0.00 & $-0.03^{*}$ & -0.10 & $-0.49^{*}$ & $-0.33^{*}$ & $-0.17^{*}$ & 1.00 & \\
\hline (20) minor & $-0.07^{*}$ & $-0.07^{*}$ & $-0.03^{*}$ & $0.10^{*}$ & $0.18^{*}$ & 0.05 & $0.09^{*}$ & $0.01^{*}$ & $0.00^{*}$ & $0.04^{*}$ & $0.03^{*}$ & $0.02^{*}$ & $-0.06^{*}$ & $0.06^{*}$ & $-0.51^{*}$ & $0.22^{*}$ & $0.06^{*}$ & $0.48^{*}$ & $-0.24^{*}$ & 1.00 \\
\hline (21) marr & $0.08^{*}$ & $0.07^{*}$ & $0.09^{*}$ & $-0.17^{*}$ & $-0.26^{*}$ & $-0.09^{*}$ & $-0.10^{*}$ & $0.01^{*}$ & $0.01^{*}$ & $-0.05^{*}$ & $-0.06^{*}$ & -0.01 & $0.02^{*}$ & $-0.06^{*}$ & $0.44^{*}$ & $-0.50^{*}$ & $-0.21^{*}$ & $-0.30^{*}$ & $0.50^{*}$ & $-0.78^{*}$ \\
\hline
\end{tabular}


Table 3. Excess Hedge Fund Risk-taking Sorted by Local Religiosity

This table reports average excess fund total and idiosyncratic risk sorted by local religiosity. Each year during 1996-2013, we sort hedge funds into quintiles based on local religiosity. We then calculate the means of excess fund total and idiosyncratic risk for each quintile, and report the time-series means of both excess risk measures. We also report the differences between the top and bottom religiosity quintiles and the associated t-statistics. All of the variables are defined in Appendix A and winsorized at the upper and lower $1 \%$ levels. We obtain excess risk measures of a fund by subtracting the annual median values within the fund's investment strategy. ${ }^{* * *},{ }^{* *},{ }^{*}$ denote significance at the $1 \%, 5 \%$, and $10 \%$ levels in a two-tailed test, respectively.

\begin{tabular}{|c|c|c|c|c|c|c|c|}
\hline & Low & 2 & 3 & 4 & High & High-Low & $t$-stat \\
\hline Mean E & 0.0021 & -0.0024 & 0.0009 & -0.0014 & -0.0006 & $-0.0027^{* * *}$ & -2.7678 \\
\hline Mean Excess Idiosyncratic Risk & 0.0010 & -0.0011 & -0.0001 & -0.0009 & 0.0000 & $-0.0010^{* *}$ & -1.9200 \\
\hline
\end{tabular}




\section{Table 4. Regression Analyses of Hedge Fund Risk-taking on Local Religiosity}

This table presents regression analyses of hedge fund risk-taking on local religiosity during 1996-2013. Panel A provides fixedeffects panel regression results using strategy and year fixed effects. Panel B provides Fama-MacBeth regression results, where each year we run cross-sectional regressions of hedge fund risk measures on local religiosity, and then calculate the time-series averages of regression coefficients. All of the variables are defined in Appendix A and winsorized at the upper and lower 1\% levels. P-values (in parentheses) are calculated using robust standard errors. ${ }^{* * *},{ }^{* *}$, and ${ }^{*}$ indicate significance at the $1 \%, 5 \%$, and $10 \%$ levels in a two-tailed test, respectively.

\begin{tabular}{|c|c|c|c|c|}
\hline \multicolumn{5}{|c|}{ Panel A. Strategy and Year Fixed Effects Panel Regressions } \\
\hline & $(1)$ & $(2)$ & $(3)$ & $(4)$ \\
\hline & Total Risk & Idiosyncratic Risk & Total Risk & Idiosyncratic Risk \\
\hline \multirow[t]{2}{*}{ REL } & $-0.013^{* * *}$ & $-0.003^{* *}$ & $-0.008^{* * *}$ & -0.002 \\
\hline & $(0.000)$ & $(0.010)$ & $(0.002)$ & $(0.188)$ \\
\hline \multirow[t]{2}{*}{ log_fund_assets } & & & $-0.143^{* * *}$ & $-0.017^{* * *}$ \\
\hline & & & $(0.000)$ & $(0.008)$ \\
\hline \multirow[t]{2}{*}{ log_firm_assets } & & & $-0.064^{* * *}$ & $-0.035^{* * *}$ \\
\hline & & & $(0.000)$ & $(0.000)$ \\
\hline \multirow[t]{2}{*}{ log_advance_notice } & & & -0.000 & $-0.000^{*}$ \\
\hline & & & $(0.876)$ & $(0.051)$ \\
\hline \multirow[t]{2}{*}{ log_minimum_investment } & & & $-0.002^{* * *}$ & $-0.001^{* * *}$ \\
\hline & & & $(0.000)$ & $(0.000)$ \\
\hline \multirow[t]{2}{*}{ management_fee } & & & $0.003^{* * *}$ & $0.002^{* * *}$ \\
\hline & & & $(0.000)$ & $(0.000)$ \\
\hline \multirow[t]{2}{*}{ incentive_fee } & & & -0.000 & $0.000^{* * *}$ \\
\hline & & & $(0.288)$ & $(0.000)$ \\
\hline \multirow[t]{2}{*}{ high_watermark } & & & $0.002^{* * *}$ & $0.001^{* * *}$ \\
\hline & & & $(0.000)$ & $(0.000)$ \\
\hline \multirow[t]{2}{*}{ log_lockup } & & & $0.001^{* * *}$ & $0.000^{* * *}$ \\
\hline & & & $(0.000)$ & $(0.000)$ \\
\hline \multirow[t]{2}{*}{ hurdle_rate } & & & -0.000 & 0.000 \\
\hline & & & $(0.765)$ & $(0.227)$ \\
\hline \multirow[t]{2}{*}{ leverage } & & & $0.004^{* * *}$ & $0.002^{* * *}$ \\
\hline & & & $(0.000)$ & $(0.000)$ \\
\hline \multirow[t]{2}{*}{ audit } & & & $0.001^{* *}$ & $0.002^{* * *}$ \\
\hline & & & $(0.046)$ & $(0.000)$ \\
\hline \multirow[t]{2}{*}{ age } & $0.000^{*}$ & $0.000^{* * *}$ & $0.000^{* *}$ & $0.000^{* * *}$ \\
\hline & $(0.072)$ & $(0.000)$ & $(0.041)$ & $(0.001)$ \\
\hline \multirow[t]{2}{*}{ edu } & $-0.000^{* * * *}$ & -0.000 & -0.000 & -0.000 \\
\hline & $(0.000)$ & $(0.196)$ & $(0.108)$ & $(0.623)$ \\
\hline \multirow[t]{2}{*}{ log_income } & $0.004^{* * *}$ & 0.001 & 0.001 & 0.000 \\
\hline & $(0.003)$ & $(0.120)$ & $(0.504)$ & $(0.742)$ \\
\hline \multirow[t]{2}{*}{ log_ttlpop } & $-0.001^{* * *}$ & $-0.000^{* * *}$ & $-0.001^{* * *}$ & $-0.000^{* *}$ \\
\hline & $(0.000)$ & $(0.001)$ & $(0.000)$ & $(0.024)$ \\
\hline \multirow[t]{2}{*}{$\mathrm{mf}$} & -0.005 & 0.005 & -0.006 & $0.006^{*}$ \\
\hline & $(0.362)$ & $(0.100)$ & $(0.277)$ & $(0.062)$ \\
\hline \multirow[t]{2}{*}{ minor } & -0.002 & $-0.003^{* *}$ & -0.001 & $-0.004^{* * *}$ \\
\hline & $(0.432)$ & $(0.031)$ & $(0.683)$ & $(0.007)$ \\
\hline \multirow[t]{2}{*}{ marr } & 0.009 & -0.006 & -0.003 & $-0.016^{* *}$ \\
\hline & $(0.462)$ & $(0.381)$ & $(0.806)$ & $(0.020)$ \\
\hline \multirow[t]{2}{*}{ Constant } & $0.021^{*}$ & $-0.012^{* *}$ & $0.073^{* * *}$ & 0.005 \\
\hline & $(0.055)$ & $(0.036)$ & $(0.000)$ & $(0.439)$ \\
\hline Strategy Fixed Effects & Yes & Yes & Yes & Yes \\
\hline Year Fixed Effects & Yes & Yes & Yes & Yes \\
\hline Observations & 31,190 & 31,190 & 26,315 & 26,315 \\
\hline R-squared & 0.204 & 0.152 & 0.242 & 0.172 \\
\hline
\end{tabular}




\begin{tabular}{|c|c|c|c|c|}
\hline \multicolumn{5}{|c|}{ Panel B. Fama-MacBeth Regressions } \\
\hline & $(1)$ & $(2)$ & (3) & (4) \\
\hline & Total Risk & Idiosyncratic Risk & Total Risk & Idiosyncratic Risk \\
\hline \multirow[t]{2}{*}{ REL } & $-0.014^{* * *}$ & $-0.006^{* *}$ & $-0.015^{* * *}$ & $-0.006^{* *}$ \\
\hline & $(0.004)$ & $(0.013)$ & $(0.007)$ & $(0.024)$ \\
\hline \multirow[t]{2}{*}{ log_fund_assets } & & & $-0.225^{* * *}$ & $-0.037^{* * *}$ \\
\hline & & & $(0.000)$ & $(0.004)$ \\
\hline \multirow[t]{2}{*}{ log_firm_assets } & & & $-0.079^{* * *}$ & $-0.036^{* * *}$ \\
\hline & & & $(0.000)$ & $(0.000)$ \\
\hline \multirow[t]{2}{*}{ log_advance_notice } & & & $-0.003^{* * *}$ & $-0.001^{* * *}$ \\
\hline & & & $(0.000)$ & $(0.000)$ \\
\hline \multirow[t]{2}{*}{ log_minimum_investment } & & & $-0.002^{* * *}$ & $-0.001^{* * *}$ \\
\hline & & & $(0.000)$ & $(0.000)$ \\
\hline \multirow[t]{2}{*}{ management_fee } & & & $0.003^{* * *}$ & $0.002^{* * *}$ \\
\hline & & & $(0.000)$ & $(0.000)$ \\
\hline \multirow[t]{2}{*}{ incentive_fee } & & & $0.000^{* * *}$ & $0.000^{* * *}$ \\
\hline & & & $(0.000)$ & $(0.000)$ \\
\hline \multirow[t]{2}{*}{ high_watermark } & & & $0.002^{* * *}$ & $0.001^{* * *}$ \\
\hline & & & $(0.006)$ & $(0.001)$ \\
\hline \multirow[t]{2}{*}{ log_lockup } & & & $0.002^{* * *}$ & $0.000^{* * *}$ \\
\hline & & & $(0.000)$ & $(0.003)$ \\
\hline \multirow[t]{2}{*}{ hurdle_rate } & & & $-0.003^{* * *}$ & $-0.001^{* *}$ \\
\hline & & & $(0.001)$ & $(0.029)$ \\
\hline \multirow[t]{2}{*}{ leverage } & & & $0.005^{* * *}$ & $0.002^{* * *}$ \\
\hline & & & $(0.000)$ & $(0.000)$ \\
\hline \multirow[t]{2}{*}{ audit } & & & 0.001 & $0.002^{* *}$ \\
\hline & & & $(0.307)$ & $(0.018)$ \\
\hline \multirow[t]{2}{*}{ age } & $0.000^{*}$ & $0.000^{* *}$ & $0.000^{*}$ & $0.000^{*}$ \\
\hline & $(0.051)$ & $(0.046)$ & $(0.051)$ & $(0.057)$ \\
\hline \multirow[t]{2}{*}{ edu } & $0.000^{* *}$ & $0.000^{* *}$ & $0.000^{* *}$ & $0.000^{*}$ \\
\hline & $(0.017)$ & $(0.044)$ & $(0.013)$ & $(0.060)$ \\
\hline \multirow[t]{2}{*}{ log_income } & $-0.011^{* * * *}$ & $-0.004^{*}$ & $-0.007^{* *}$ & -0.003 \\
\hline & $(0.007)$ & $(0.063)$ & $(0.027)$ & $(0.122)$ \\
\hline \multirow[t]{2}{*}{ log_ttlpop } & $-0.001^{* * * *}$ & $-0.000^{* * * *}$ & $-0.001^{* *}$ & -0.000 \\
\hline & $(0.000)$ & $(0.002)$ & $(0.019)$ & $(0.600)$ \\
\hline \multirow[t]{2}{*}{$\mathrm{mf}$} & 0.013 & 0.006 & 0.002 & 0.004 \\
\hline & $(0.186)$ & $(0.142)$ & $(0.833)$ & $(0.394)$ \\
\hline \multirow[t]{2}{*}{ minor } & 0.006 & -0.002 & 0.003 & $-0.006^{* *}$ \\
\hline & $(0.155)$ & $(0.310)$ & $(0.257)$ & $(0.027)$ \\
\hline \multirow[t]{2}{*}{ marr } & $0.061^{* *}$ & 0.022 & 0.018 & -0.014 \\
\hline & $(0.015)$ & $(0.105)$ & $(0.373)$ & $(0.383)$ \\
\hline \multirow[t]{2}{*}{ Constant } & $0.130^{* * *}$ & $0.047^{* * *}$ & $0.147^{* * *}$ & $0.057^{* * *}$ \\
\hline & $(0.001)$ & $(0.006)$ & $(0.000)$ & $(0.001)$ \\
\hline Observations & 31,190 & 31,190 & 26,315 & 26,315 \\
\hline R-squared & 0.024 & 0.018 & 0.144 & 0.105 \\
\hline
\end{tabular}




\section{Table 5. Regression Analyses of Local Religiosity and Hedge Fund Risk-taking by Fund Strategy}

This table reports fixed-effects panel regressions and Fama-MacBeth regression results of hedge fund risk-taking on local religiosity during 1996-2013 by fund strategy. Strategy (1) is Equity Hedge, Strategy (2) is Event-Driven, Strategy (3) is Fund of Funds, Strategy (4) is Macro, and Strategy (5) is Relative Value. Strategies (1) through (3) are semi-directional, (4) is directional, and (5) is non-directional investment strategies. All of the variables are defined in Appendix A and winsorized at the upper and lower 1\% levels. P-values (in parentheses) are calculated using robust standard errors. All control variables are included in regressions; for brevity, only the coefficients on REL are presented. ${ }^{* * *},{ }^{* *}$, and ${ }^{*}$ indicate significance at the $1 \%, 5 \%$, and $10 \%$ levels in a two-tailed test, respectively.

\begin{tabular}{|c|c|c|c|c|c|}
\hline & & \multicolumn{2}{|c|}{ Fixed Effects } & \multicolumn{2}{|c|}{ Fama-MacBeth } \\
\hline & & (1) & $(2)$ & (3) & (4) \\
\hline & & Total Risk & Idiosyncratic Risk & Total Risk & Idiosyncratic Risk \\
\hline \multirow{5}{*}{$\begin{array}{l}\text { Strategy (1): } \\
\text { Equity Hedge }\end{array}$} & REL & $-0.029^{* * *}$ & $-0.012^{* * *}$ & $-0.038^{* * *}$ & $-0.019^{* * *}$ \\
\hline & & $(0.000)$ & $(0.000)$ & $(0.000)$ & $(0.000)$ \\
\hline & Year Fixed Effects & Yes & Yes & No & No \\
\hline & Observations & 10,344 & 10,344 & 10,344 & 10,344 \\
\hline & R-squared & 0.222 & 0.142 & 0.132 & 0.097 \\
\hline \multirow{5}{*}{$\begin{array}{l}\text { Strategy (2): } \\
\text { Event-Driven }\end{array}$} & REL & $-0.023^{*}$ & -0.006 & $-0.043^{* * *}$ & -0.006 \\
\hline & & $(0.085)$ & $(0.412)$ & $(0.004)$ & $(0.370)$ \\
\hline & Year Fixed Effects & Yes & Yes & No & No \\
\hline & Observations & 2,974 & 2,974 & 2,974 & 2,974 \\
\hline & R-squared & 0.160 & 0.110 & 0.240 & 0.196 \\
\hline \multirow{5}{*}{$\begin{array}{l}\text { Strategy (3): } \\
\text { Fund of Funds }\end{array}$} & REL & 0.004 & 0.002 & 0.008 & 0.004 \\
\hline & & $(0.199)$ & $(0.300)$ & $(0.343)$ & $(0.437)$ \\
\hline & Year Fixed Effects & Yes & Yes & No & No \\
\hline & Observations & 4,816 & 4,816 & 4,816 & 4,816 \\
\hline & R-squared & 0.313 & 0.238 & 0.228 & 0.235 \\
\hline \multirow{5}{*}{$\begin{array}{l}\text { Strategy (4): } \\
\text { Macro }\end{array}$} & REL & $0.024^{* * *}$ & $0.017^{* * *}$ & $0.039^{* * *}$ & $0.016^{* * *}$ \\
\hline & & $(0.000)$ & $(0.000)$ & $(0.009)$ & $(0.005)$ \\
\hline & Year Fixed Effects & Yes & Yes & No & No \\
\hline & Observations & 4,056 & 4,056 & 4,056 & 4,056 \\
\hline & R-squared & 0.128 & 0.117 & 0.227 & 0.201 \\
\hline \multirow{5}{*}{$\begin{array}{l}\text { Strategy (5): } \\
\text { Relative Value }\end{array}$} & REL & 0.008 & 0.004 & $0.030^{* *}$ & $0.008^{* *}$ \\
\hline & & $(0.118)$ & $(0.241)$ & $(0.022)$ & $(0.033)$ \\
\hline & Year Fixed Effects & Yes & Yes & No & No \\
\hline & Observations & 4,125 & 4,125 & 4,125 & 4,125 \\
\hline & R-squared & 0.262 & 0.179 & 0.202 & 0.178 \\
\hline \multirow{5}{*}{$\begin{array}{l}\text { Strategies } \\
(1),(2), \&(3)\end{array}$} & REL & $-0.020^{* * *}$ & $-0.008^{* * *}$ & $-0.031^{* * *}$ & $-0.013^{* * *}$ \\
\hline & & $(0.000)$ & $(0.000)$ & $(0.000)$ & $(0.001)$ \\
\hline & $($ Strategy $\times$ Year $) \mathrm{FE}$ & Yes & Yes & No & No \\
\hline & Observations & 18,134 & 18,134 & 18,134 & 18,134 \\
\hline & R-squared & 0.293 & 0.192 & 0.153 & 0.113 \\
\hline
\end{tabular}




\section{Table 6. Instrumental Variables (IV) Regressions of Hedge Fund Risk-taking on Local Religiosity}

This table shows instrumental variable (IV) regression results of hedge fund risk-taking on local religiosity during 1996-2013. The first stage regresses local religiosity (REL) on the two instrumental variables, lagged 3-year religiosity (REL_lag3) and lagged 3year total population of the county (ttlpop_lag3) in millions. The second stage regresses hedge fund risk-taking on the fitted value of REL from the first stage. The two stages are jointly estimated. All of the variables are defined in Appendix A and winsorized at the upper and lower $1 \%$ levels. P-values (in parentheses) are calculated using robust standard errors. Constants are omitted. ${ }^{* * *},{ }^{* *}$, and ${ }^{*}$ indicate significance at the $1 \%, 5 \%$, and $10 \%$ levels in a two-tailed test, respectively.

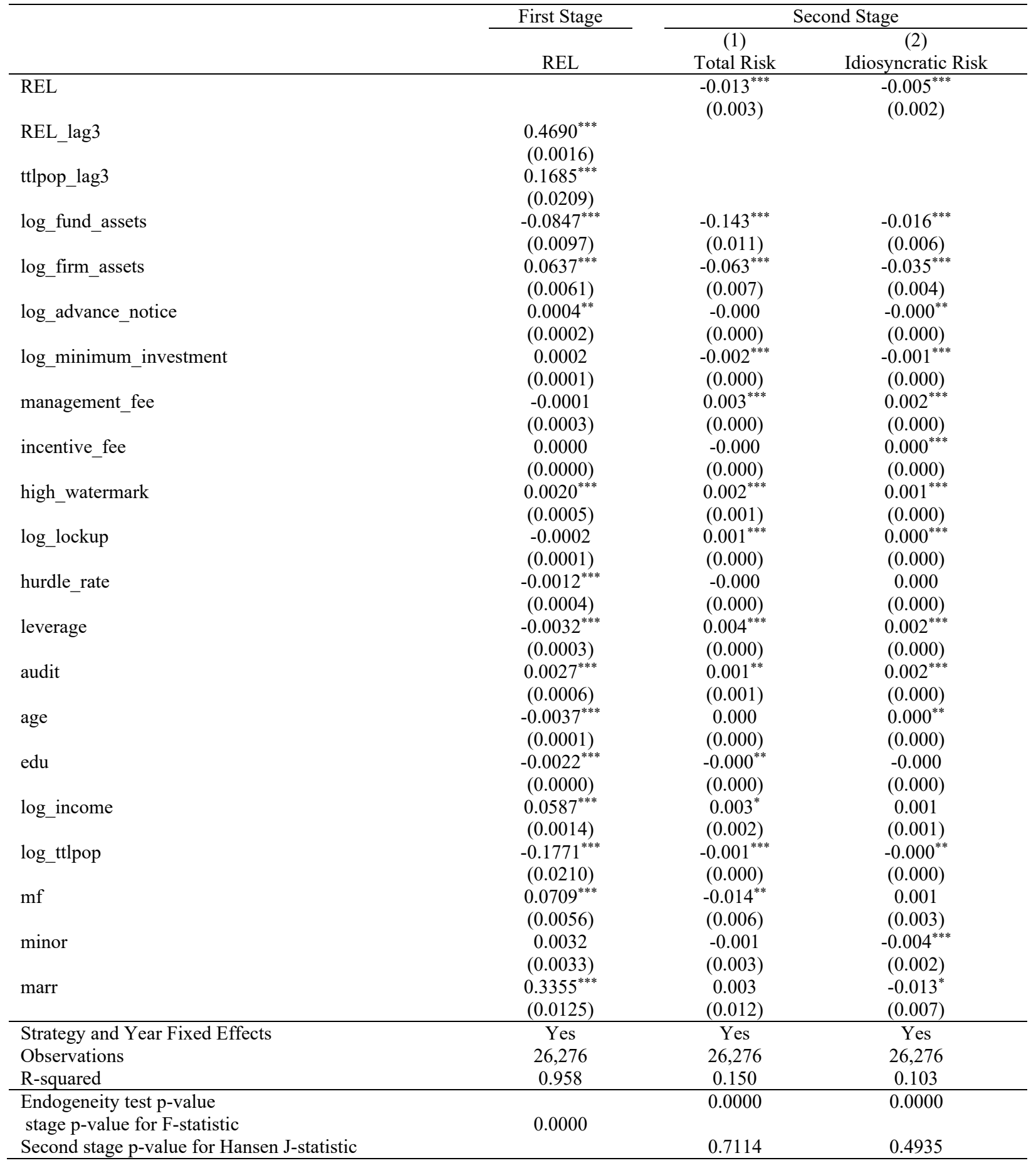




\section{Table 7. Local Religiosity versus Fund Managers' College-Location Religiosity}

This table reports regression results of hedge fund risk-taking on local religiosity (REL) versus fund managers' undergraduate college location religiosity (College REL) during 1996-2013. Panel A uses the full sample (including strategies 1 (Equity Hedge), 2 (Event-Driven), and 3 (Fund of Funds)) where we can manually identify fund managers' undergraduate colleges in the U.S., while Panel B uses the subsample where the undergraduate colleges attended by fund managers are in different U.S. Census Bureau regions than fund locations. All of the variables are defined in Appendix A and winsorized at the upper and lower 1\% levels. Demographic variables associated with fund managers' college locations are also controlled in all tests. P-values (in parentheses) are calculated using robust standard errors. Constants are omitted. ${ }^{* * *}{ }^{* *}$, and ${ }^{*}$ indicate significance at the $1 \%, 5 \%$, and $10 \%$ levels in a two-tailed test, respectively.

\begin{tabular}{|c|c|c|c|c|c|c|c|c|}
\hline & \multicolumn{4}{|c|}{ Panel A. Full Sample } & \multicolumn{4}{|c|}{ Panel B. Subsample of Different Regions } \\
\hline & (1) & (2) & (3) & (4) & (5) & $(6)$ & (7) & $(8)$ \\
\hline & Total Risk & Idiosyncratic Risk & Total Risk & Idiosyncratic Risk & Total Risk & Idiosyncratic Risk & Total Risk & Idiosyncratic Risk \\
\hline \multirow[t]{2}{*}{ REL } & & & $-0.021^{* * *}$ & $-0.007^{* *}$ & & & $-0.021^{* * *}$ & $-0.007^{* *}$ \\
\hline & & & $(0.000)$ & $(0.013)$ & & & $(0.000)$ & $(0.038)$ \\
\hline \multirow[t]{2}{*}{ College REL } & $-0.009^{* * *}$ & $-0.006^{* * *}$ & $-0.008^{* *}$ & $-0.005^{* * *}$ & $-0.008^{*}$ & -0.003 & $-0.008^{*}$ & -0.003 \\
\hline & $(0.008)$ & $(0.002)$ & $(0.020)$ & $(0.003)$ & $(0.052)$ & $(0.188)$ & $(0.066)$ & $(0.158)$ \\
\hline \multirow[t]{2}{*}{ log_fund_assets } & $-0.045^{*}$ & 0.021 & $-0.045^{*}$ & $0.023^{*}$ & $-0.050^{*}$ & 0.020 & $-0.048^{*}$ & 0.023 \\
\hline & $(0.074)$ & $(0.130)$ & $(0.078)$ & $(0.093)$ & $(0.082)$ & $(0.201)$ & $(0.097)$ & $(0.140)$ \\
\hline \multirow[t]{2}{*}{ log_firm_assets } & $-0.071^{* * *}$ & $-0.038^{* * *}$ & $-0.068^{* * *}$ & $-0.037^{* * *}$ & $-0.072^{* * *}$ & $-0.037^{* * *}$ & $-0.066^{* * *}$ & $-0.036^{* * *}$ \\
\hline & $(0.000)$ & $(0.000)$ & $(0.000)$ & $(0.000)$ & $(0.000)$ & $(0.000)$ & $(0.000)$ & $(0.000)$ \\
\hline \multirow[t]{2}{*}{ log_advance_notice } & 0.001 & 0.000 & 0.001 & 0.000 & -0.001 & -0.001 & $-0.001^{* *}$ & $-0.001^{*}$ \\
\hline & $(0.116)$ & $(0.135)$ & $(0.221)$ & $(0.232)$ & $(0.103)$ & $(0.136)$ & $(0.047)$ & $(0.074)$ \\
\hline \multirow[t]{2}{*}{ log_minimum_investment } & $-0.003^{* * *}$ & $-0.001^{* * *}$ & $-0.003^{* * *}$ & $-0.001^{* * *}$ & $-0.003^{* * *}$ & $-0.001^{* * *}$ & $-0.003^{* * *}$ & $-0.001^{* * *}$ \\
\hline & $(0.000)$ & $(0.000)$ & $(0.000)$ & $(0.000)$ & $(0.000)$ & $(0.000)$ & $(0.000)$ & $(0.000)$ \\
\hline \multirow[t]{2}{*}{ management_fee } & $0.003^{* * *}$ & $0.002^{* * *}$ & $0.003^{* * *}$ & $0.002^{* * *}$ & $0.004^{* * *}$ & $0.002^{* * * *}$ & $0.004^{* * *}$ & $0.002^{* * *}$ \\
\hline & $(0.002)$ & $(0.000)$ & $(0.003)$ & $(0.000)$ & $(0.000)$ & $(0.000)$ & $(0.000)$ & $(0.000)$ \\
\hline \multirow[t]{2}{*}{ incentive_fee } & $-0.000^{* *}$ & 0.000 & $-0.000^{* * *}$ & 0.000 & $-0.000^{* * *}$ & -0.000 & $-0.000^{* * *}$ & -0.000 \\
\hline & $(0.017)$ & $(0.222)$ & $(0.010)$ & $(0.387)$ & $(0.000)$ & $(0.871)$ & $(0.000)$ & $(0.490)$ \\
\hline \multirow[t]{2}{*}{ high_watermark } & 0.001 & 0.001 & 0.001 & 0.001 & 0.000 & 0.001 & 0.000 & 0.001 \\
\hline & $(0.461)$ & $(0.322)$ & $(0.523)$ & $(0.268)$ & $(0.781)$ & $(0.189)$ & $(0.815)$ & $(0.119)$ \\
\hline \multirow[t]{2}{*}{ log_lockup } & $0.003^{* * *}$ & $0.001^{* * *}$ & $0.003^{* * *}$ & $0.001^{* * *}$ & $0.002^{* * *}$ & $0.001^{* * *}$ & $0.002^{* * *}$ & $0.001^{* * *}$ \\
\hline & $(0.000)$ & $(0.000)$ & $(0.000)$ & $(0.000)$ & $(0.000)$ & $(0.000)$ & $(0.000)$ & $(0.000)$ \\
\hline \multirow[t]{2}{*}{ hurdle_rate } & -0.001 & -0.000 & -0.001 & -0.000 & -0.000 & -0.001 & 0.000 & -0.000 \\
\hline & $(0.329)$ & $(0.399)$ & $(0.442)$ & $(0.604)$ & $(0.774)$ & $(0.260)$ & $(0.982)$ & $(0.476)$ \\
\hline \multirow[t]{2}{*}{ leverage } & $0.005^{* * *}$ & $0.002^{* * *}$ & $0.005^{* * *}$ & $0.002^{* * *}$ & $0.006^{* * *}$ & $0.003^{* * *}$ & $0.006^{* * *}$ & $0.002^{* * *}$ \\
\hline & $(0.000)$ & $(0.000)$ & $(0.000)$ & $(0.000)$ & $(0.000)$ & $(0.000)$ & $(0.000)$ & $(0.000)$ \\
\hline \multirow[t]{2}{*}{ audit } & $0.005^{* * *}$ & $0.004^{* * *}$ & $0.004^{* * *}$ & $0.004^{* * *}$ & $0.008^{* * *}$ & $0.005^{* * *}$ & $0.008^{* * *}$ & $0.005^{* * *}$ \\
\hline & $(0.002)$ & $(0.000)$ & $(0.004)$ & $(0.000)$ & $(0.000)$ & $(0.000)$ & $(0.000)$ & $(0.000)$ \\
\hline
\end{tabular}




\begin{tabular}{|c|c|c|c|c|c|c|c|c|}
\hline College age & $\begin{array}{c}0.001^{* * *} \\
(0.003)\end{array}$ & $\begin{array}{l}0.000^{* * *} \\
(0.007)\end{array}$ & $\begin{array}{l}0.001^{* * *} \\
(0.006)\end{array}$ & $\begin{array}{l}0.000^{* *} \\
(0.014)\end{array}$ & $\begin{array}{l}0.001^{* * *} \\
(0.000)\end{array}$ & $\begin{array}{l}0.001^{* * *} \\
(0.000)\end{array}$ & $\begin{array}{c}0.001^{* * *} \\
(0.000)\end{array}$ & $\begin{array}{l}0.001^{* * *} \\
(0.000)\end{array}$ \\
\hline \multirow[t]{2}{*}{ College edu } & $-0.000^{* *}$ & $-0.000^{*}$ & $-0.000^{* * *}$ & $-0.000^{*}$ & -0.000 & 0.000 & -0.000 & 0.000 \\
\hline & $(0.029)$ & $(0.080)$ & $(0.010)$ & $(0.058)$ & $(0.280)$ & $(0.785)$ & $(0.143)$ & $(0.870)$ \\
\hline \multirow[t]{2}{*}{ College log_income } & -0.000 & 0.000 & -0.000 & 0.000 & -0.002 & -0.001 & -0.001 & -0.001 \\
\hline & $(0.741)$ & $(0.704)$ & $(0.968)$ & $(0.594)$ & $(0.270)$ & $(0.132)$ & $(0.410)$ & $(0.181)$ \\
\hline \multirow[t]{2}{*}{ College log_ttlpop } & 0.000 & 0.000 & -0.000 & 0.000 & $-0.001^{* *}$ & $-0.000^{*}$ & $-0.001^{* * *}$ & $-0.000^{* *}$ \\
\hline & $(0.984)$ & $(0.855)$ & $(0.969)$ & $(0.910)$ & $(0.015)$ & $(0.074)$ & $(0.007)$ & $(0.045)$ \\
\hline \multirow[t]{2}{*}{ College mf } & -0.009 & -0.004 & -0.009 & -0.004 & -0.005 & -0.001 & -0.008 & -0.003 \\
\hline & $(0.244)$ & $(0.378)$ & $(0.263)$ & $(0.400)$ & $(0.605)$ & $(0.783)$ & $(0.394)$ & $(0.591)$ \\
\hline \multirow[t]{2}{*}{ College minor } & 0.003 & -0.002 & 0.002 & -0.003 & -0.004 & 0.000 & -0.003 & 0.000 \\
\hline & $(0.606)$ & $(0.452)$ & $(0.691)$ & $(0.375)$ & $(0.637)$ & $(0.988)$ & $(0.669)$ & $(0.998)$ \\
\hline \multirow[t]{2}{*}{ College marr } & 0.017 & 0.006 & 0.016 & 0.004 & 0.001 & 0.004 & 0.000 & 0.004 \\
\hline & $(0.155)$ & $(0.395)$ & $(0.207)$ & $(0.504)$ & $(0.967)$ & $(0.626)$ & $(0.978)$ & $(0.666)$ \\
\hline \multirow[t]{2}{*}{ age } & $-0.000^{* *}$ & -0.000 & $-0.001^{* * *}$ & -0.000 & $-0.001^{* *}$ & -0.000 & $-0.001^{* * *}$ & $-0.000^{*}$ \\
\hline & $(0.027)$ & $(0.412)$ & $(0.001)$ & $(0.118)$ & $(0.021)$ & $(0.248)$ & $(0.001)$ & $(0.088)$ \\
\hline \multirow[t]{2}{*}{ edu } & $0.000^{* * *}$ & $0.000^{* * *}$ & 0.000 & 0.000 & 0.000 & $0.000^{*}$ & -0.000 & 0.000 \\
\hline & $(0.010)$ & $(0.002)$ & $(0.879)$ & $(0.227)$ & $(0.429)$ & $(0.090)$ & $(0.253)$ & $(0.689)$ \\
\hline \multirow[t]{2}{*}{ log_income } & 0.000 & -0.000 & $0.007^{* *}$ & 0.002 & 0.002 & 0.000 & $0.009^{* * *}$ & 0.003 \\
\hline & $(0.852)$ & $(0.955)$ & $(0.015)$ & $(0.144)$ & $(0.456)$ & $(0.792)$ & $(0.006)$ & $(0.144)$ \\
\hline \multirow[t]{2}{*}{ log_ttlpop } & -0.000 & -0.000 & 0.001 & 0.000 & 0.000 & 0.000 & $0.002^{* * *}$ & $0.001^{*}$ \\
\hline & $(0.659)$ & $(0.701)$ & $(0.190)$ & $(0.597)$ & $(0.397)$ & $(0.467)$ & $(0.007)$ & $(0.052)$ \\
\hline \multirow[t]{2}{*}{$\mathrm{mf}$} & 0.009 & $0.011^{* *}$ & -0.017 & 0.002 & $0.032^{* * *}$ & $0.022^{* * *}$ & 0.007 & $0.015^{*}$ \\
\hline & $(0.323)$ & $(0.017)$ & $(0.116)$ & $(0.695)$ & $(0.006)$ & $(0.000)$ & $(0.623)$ & $(0.052)$ \\
\hline \multirow[t]{2}{*}{ minor } & $0.014^{* *}$ & 0.003 & $0.012^{* *}$ & 0.002 & 0.006 & 0.001 & 0.003 & 0.000 \\
\hline & $(0.014)$ & $(0.352)$ & $(0.041)$ & $(0.488)$ & $(0.389)$ & $(0.771)$ & $(0.667)$ & $(0.991)$ \\
\hline \multirow[t]{2}{*}{ marr } & $0.071^{* * *}$ & $0.023^{*}$ & $0.084^{* * *}$ & $0.027^{*}$ & 0.040 & 0.007 & $0.057^{*}$ & 0.012 \\
\hline & $(0.005)$ & $(0.094)$ & $(0.001)$ & $(0.055)$ & $(0.171)$ & $(0.652)$ & $(0.057)$ & $(0.479)$ \\
\hline \multirow[t]{2}{*}{ Constant } & $0.049^{*}$ & -0.011 & 0.018 & -0.020 & 0.032 & -0.021 & -0.004 & $-0.032^{*}$ \\
\hline & $(0.058)$ & $(0.446)$ & $(0.492)$ & $(0.152)$ & $(0.309)$ & $(0.209)$ & $(0.894)$ & $(0.061)$ \\
\hline Strategy Fixed Effects & Yes & Yes & Yes & Yes & Yes & Yes & Yes & Yes \\
\hline Year Fixed Effects & Yes & Yes & Yes & Yes & Yes & Yes & Yes & Yes \\
\hline Observations & 5,817 & 5,817 & 5,789 & 5,789 & 4,215 & 4,215 & 4,187 & 4,187 \\
\hline R-squared & 0.273 & 0.190 & 0.275 & 0.191 & 0.274 & 0.193 & 0.276 & 0.194 \\
\hline
\end{tabular}




\section{Table 8. Analysis of Financial Crises}

This table reports fixed effects panel regressions of hedge fund risk-taking on local religiosity (REL), on subsamples partitioned on financial crisis period. Crisis refers to years of 1998, 2007, and 2008; and Non-Crisis otherwise. The sample includes strategies 1 (Equity Hedge), 2 (Event-Driven), and 3 (Fund of Funds). All of the variables are defined in Appendix A and winsorized at the upper and lower $1 \%$ levels. P-values (in parentheses) are calculated using robust standard errors. Constants are omitted. ${ }^{* * *},{ }^{* *}$, and ${ }^{*}$ indicate significance at the $1 \%, 5 \%$, and $10 \%$ levels in a two-tailed test, respectively.

\begin{tabular}{|c|c|c|c|c|}
\hline & \multicolumn{2}{|c|}{ Crisis } & \multicolumn{2}{|c|}{ Non-Crisis } \\
\hline & Total Risk & Idiosyncratic Risk & Total Risk & Idiosyncratic Risk \\
\hline \multirow[t]{2}{*}{ REL } & $-0.025^{* * *}$ & $-0.010^{* *}$ & $-0.019^{* * *}$ & $-0.007^{* * *}$ \\
\hline & $(0.004)$ & $(0.020)$ & $(0.000)$ & $(0.000)$ \\
\hline \multirow[t]{2}{*}{ log_fund_assets } & $-0.100^{* * *}$ & -0.004 & $-0.125^{* * *}$ & $-0.023^{* * *}$ \\
\hline & $(0.004)$ & $(0.846)$ & $(0.000)$ & $(0.004)$ \\
\hline \multirow[t]{2}{*}{ log_firm_assets } & $-0.066^{* * *}$ & $-0.033^{* * *}$ & $-0.077^{* * *}$ & $-0.038^{* * *}$ \\
\hline & $(0.002)$ & $(0.005)$ & $(0.000)$ & $(0.000)$ \\
\hline \multirow[t]{2}{*}{ log_advance_notice } & $0.002^{*}$ & $0.001^{*}$ & $0.001^{* * *}$ & $0.001^{* * *}$ \\
\hline & $(0.075)$ & $(0.066)$ & $(0.000)$ & $(0.000)$ \\
\hline \multirow[t]{2}{*}{ log_minimum_investment } & $-0.003^{* * *}$ & $-0.001^{* * *}$ & $-0.001^{* * *}$ & $-0.001^{* * *}$ \\
\hline & $(0.000)$ & $(0.000)$ & $(0.000)$ & $(0.000)$ \\
\hline \multirow[t]{2}{*}{ management_fee } & $0.003^{* *}$ & $0.002^{* * *}$ & $0.002^{* * *}$ & $0.001^{* * *}$ \\
\hline & $(0.015)$ & $(0.009)$ & $(0.000)$ & $(0.002)$ \\
\hline \multirow[t]{2}{*}{ incentive_fee } & $-0.000^{*}$ & $0.000^{*}$ & $-0.000^{* * *}$ & $0.000^{* *}$ \\
\hline & $(0.065)$ & $(0.097)$ & $(0.000)$ & $(0.043)$ \\
\hline \multirow{2}{*}{ high_watermark } & $0.003^{* *}$ & 0.001 & $0.002^{* * *}$ & $0.001^{* * *}$ \\
\hline & $(0.050)$ & $(0.156)$ & $(0.000)$ & $(0.003)$ \\
\hline \multirow[t]{2}{*}{ log_lockup } & $0.002^{* * *}$ & $0.000^{*}$ & $0.001^{* * *}$ & $0.000^{* * *}$ \\
\hline & $(0.000)$ & $(0.067)$ & $(0.000)$ & $(0.000)$ \\
\hline \multirow[t]{2}{*}{ hurdle_rate } & $0.002^{*}$ & 0.001 & -0.000 & 0.000 \\
\hline & $(0.095)$ & $(0.123)$ & $(0.981)$ & $(0.633)$ \\
\hline \multirow[t]{2}{*}{ leverage } & $0.005^{* * *}$ & $0.003^{* * *}$ & $0.003^{* * *}$ & $0.001^{* * *}$ \\
\hline & $(0.000)$ & $(0.000)$ & $(0.000)$ & $(0.000)$ \\
\hline \multirow[t]{2}{*}{ audit } & -0.002 & $0.003^{* *}$ & 0.000 & $0.001^{*}$ \\
\hline & $(0.427)$ & $(0.032)$ & $(0.895)$ & $(0.091)$ \\
\hline \multirow[t]{2}{*}{ age } & -0.000 & 0.000 & -0.000 & 0.000 \\
\hline & $(0.848)$ & $(0.342)$ & $(0.560)$ & $(0.990)$ \\
\hline \multirow[t]{2}{*}{ edu } & -0.000 & 0.000 & $-0.000^{* *}$ & -0.000 \\
\hline & $(0.101)$ & $(0.399)$ & $(0.021)$ & $(0.171)$ \\
\hline \multirow[t]{2}{*}{ log_income } & 0.004 & -0.003 & $0.004^{* *}$ & $0.002^{*}$ \\
\hline & $(0.370)$ & $(0.259)$ & $(0.034)$ & $(0.076)$ \\
\hline \multirow[t]{2}{*}{ log_ttlpop } & -0.001 & 0.000 & $-0.001^{* * *}$ & -0.000 \\
\hline & $(0.412)$ & $(0.411)$ & $(0.002)$ & $(0.692)$ \\
\hline \multirow[t]{2}{*}{$\mathrm{mf}$} & $-0.038^{* *}$ & 0.013 & $-0.020^{* * *}$ & -0.002 \\
\hline & $(0.044)$ & $(0.196)$ & $(0.005)$ & $(0.646)$ \\
\hline \multirow[t]{2}{*}{ minor } & -0.001 & $-0.009^{*}$ & -0.002 & $-0.006^{* * *}$ \\
\hline & $(0.930)$ & $(0.064)$ & $(0.514)$ & $(0.001)$ \\
\hline \multirow[t]{2}{*}{ marr } & 0.008 & -0.022 & -0.008 & $-0.023^{* * *}$ \\
\hline & $(0.842)$ & $(0.329)$ & $(0.621)$ & $(0.006)$ \\
\hline Strategy and Year FE & Yes & Yes & Yes & Yes \\
\hline Observations & 3,433 & 3,433 & 14,701 & 14,701 \\
\hline R-squared & 0.184 & 0.137 & 0.268 & 0.170 \\
\hline
\end{tabular}




\section{Table 9. Tests of Local Preference Channel: Subsample Analyses}

This table presents tests of local preference channel by estimating regressions of hedge fund risk-taking on local religiosity (REL), on subsamples partitioned on fund age (Young vs. Old) and fund size (Small vs. Large). All control variables are included in the regressions but not reported for brevity. Subsample Young (Old) contains hedge funds with an age smaller than (greater than or equal to) the sample median for each year. Subsample Small (Large) contains hedge funds with fund assets smaller than (greater than or equal to) the sample median for each year. All of the variables are defined in Appendix A and winsorized at the upper and lower $1 \%$ levels. P-values (in parentheses) are calculated using robust standard errors. Constants are omitted. ${ }^{* * *},{ }^{* *}$, and ${ }^{*}$ indicate significance at the $1 \%, 5 \%$, and $10 \%$ levels in a two-tailed test, respectively.

\begin{tabular}{|c|c|c|c|c|c|}
\hline & & \multicolumn{2}{|c|}{ Total Risk } & \multicolumn{2}{|c|}{ Idiosyncratic Risk } \\
\hline & & Fixed Effects & Fama-MacBeth & Fixed Effects & Fama-MacBeth \\
\hline \multicolumn{6}{|c|}{ Panel A. Young vs. Old Funds } \\
\hline \multirow[t]{6}{*}{ Young: } & REL & $-0.015^{* * *}$ & $-0.036^{* * *}$ & -0.003 & $-0.011^{* *}$ \\
\hline & & $(0.000)$ & $(0.005)$ & $(0.157)$ & $(0.018)$ \\
\hline & All Controls & Yes & Yes & Yes & Yes \\
\hline & Strategy and Year FE & Yes & No & Yes & No \\
\hline & Observations & 11,711 & 11,711 & 11,711 & 11,711 \\
\hline & R-squared & 0.218 & 0.158 & 0.119 & 0.092 \\
\hline \multirow[t]{6}{*}{ Old: } & REL & 0.000 & 0.000 & -0.000 & -0.004 \\
\hline & & $(0.954)$ & $(0.985)$ & $(0.828)$ & $(0.128)$ \\
\hline & All Controls & Yes & Yes & Yes & Yes \\
\hline & Strategy and Year FE & Yes & No & Yes & No \\
\hline & Observations & 14,604 & 14,604 & 14,604 & 14,604 \\
\hline & R-squared & 0.282 & 0.188 & 0.271 & 0.202 \\
\hline \multicolumn{6}{|c|}{ Panel B. Small vs. Large Funds } \\
\hline \multirow[t]{6}{*}{ Small: } & REL & $-0.013^{* * *}$ & $-0.027^{* * *}$ & $-0.004^{* *}$ & $-0.011^{* * *}$ \\
\hline & & $(0.000)$ & $(0.001)$ & $(0.033)$ & $(0.007)$ \\
\hline & All Controls & Yes & Yes & Yes & Yes \\
\hline & Strategy and Year FE & Yes & No & Yes & No \\
\hline & Observations & 12,883 & 12,883 & 12,883 & 12,883 \\
\hline & R-squared & 0.215 & 0.138 & 0.142 & 0.106 \\
\hline \multirow[t]{6}{*}{ Large: } & REL & 0.002 & -0.004 & 0.154 & 0.188 \\
\hline & & $(0.566)$ & $(0.254)$ & $(0.245)$ & $(0.131)$ \\
\hline & All Controls & Yes & Yes & Yes & Yes \\
\hline & Strategy and Year FE & Yes & No & Yes & No \\
\hline & Observations & 13,432 & 13,432 & 13,432 & 13,432 \\
\hline & R-squared & 0.266 & 0.145 & 0.218 & 0.137 \\
\hline
\end{tabular}




\section{Table 10. Local Religiosity and Hedge Fund Holdings}

This table reports regression results of average total and idiosyncratic risks of stocks held by hedge funds, holdings-based portfolio total and idiosyncratic risks, and the industry concentration of hedge fund portfolios on local religiosity in Panels A, B, and C, respectively. Strategy and year fixed effects are included in all of the regressions. All of the variables are defined in Appendix A and winsorized at the upper and lower $1 \%$ levels. P-values (in parentheses) are calculated using robust standard errors. ${ }^{* * *},{ }^{* *}$, and ${ }^{*}$ indicate significance at the $1 \%, 5 \%$, and $10 \%$ levels in a two-tailed test, respectively.

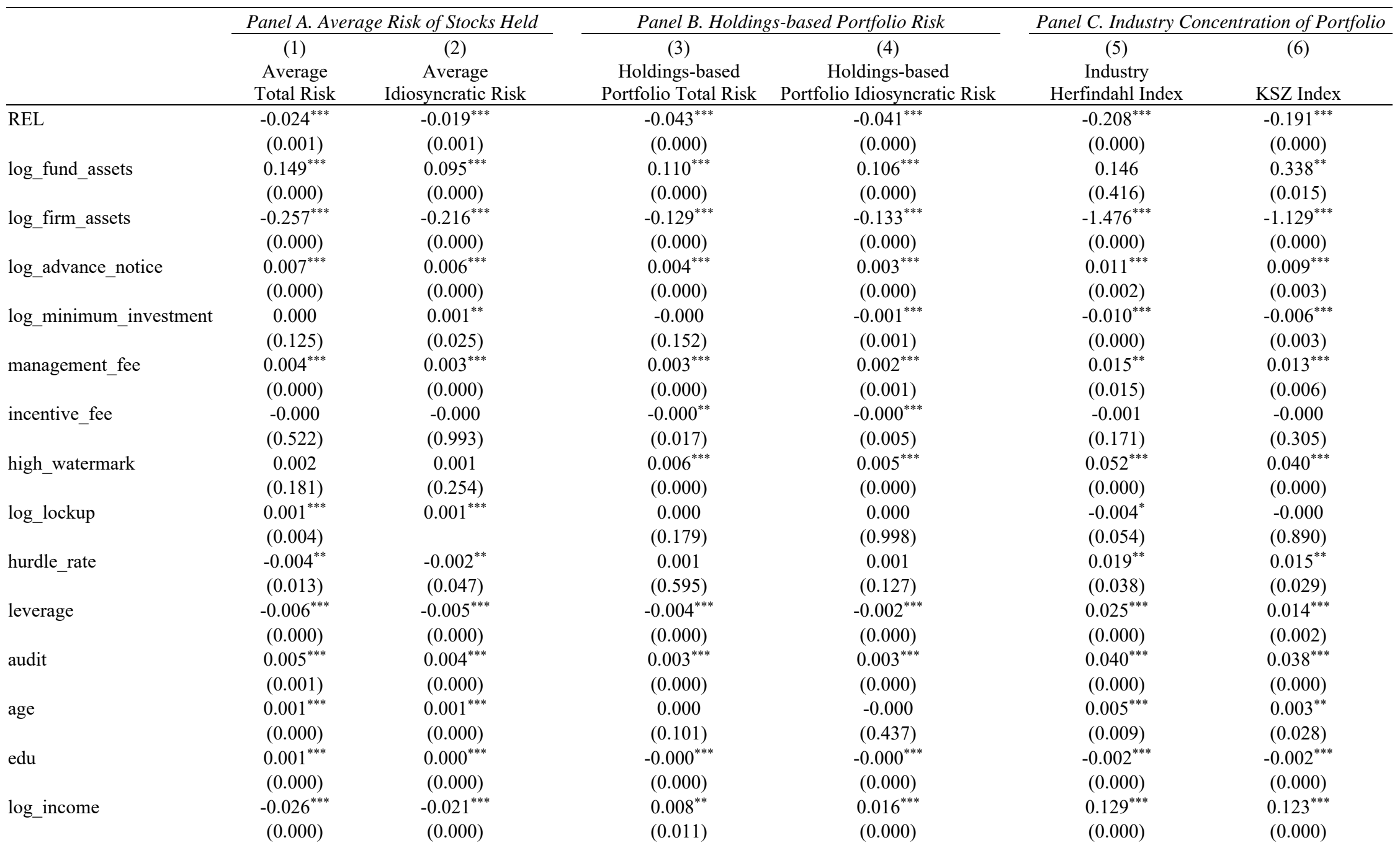




\begin{tabular}{|c|c|c|c|c|c|c|}
\hline log_ttlpop & $\begin{array}{c}0.000 \\
(0.620)\end{array}$ & $\begin{array}{l}-0.000 \\
(0.837)\end{array}$ & $\begin{array}{l}-0.000 \\
(0.991)\end{array}$ & $\begin{array}{c}0.000^{*} \\
(0.090)\end{array}$ & $\begin{array}{c}0.010^{* * *} \\
(0.001)\end{array}$ & $\begin{array}{c}0.009^{* * *} \\
(0.000)\end{array}$ \\
\hline \multirow[t]{2}{*}{$\mathrm{mf}$} & $0.075^{* * *}$ & $0.060^{* * *}$ & 0.007 & $-0.013^{*}$ & 0.130 & 0.073 \\
\hline & $(0.000)$ & $(0.000)$ & $(0.442)$ & $(0.067)$ & $(0.153)$ & $(0.287)$ \\
\hline \multirow[t]{2}{*}{ minor } & -0.005 & -0.005 & $-0.030^{* * *}$ & $-0.025^{* * *}$ & $-0.319^{* * *}$ & $-0.219^{* * *}$ \\
\hline & $(0.505)$ & $(0.402)$ & $(0.000)$ & $(0.000)$ & $(0.000)$ & $(0.000)$ \\
\hline \multirow[t]{2}{*}{ marr } & 0.001 & 0.001 & -0.013 & -0.003 & $-0.487^{* * *}$ & $-0.321^{* *}$ \\
\hline & $(0.983)$ & $(0.971)$ & $(0.550)$ & $(0.883)$ & $(0.004)$ & $(0.017)$ \\
\hline Constant & $\begin{array}{c}0.270^{* * *} \\
(0.000)\end{array}$ & $\begin{array}{c}0.234^{* * *} \\
(0.000)\end{array}$ & $\begin{array}{c}-0.003 \\
(0.908) \\
\end{array}$ & $\begin{array}{c}-0.074^{* * *} \\
(0.000)\end{array}$ & $\begin{array}{c}-0.880^{* * *} \\
(0.000)\end{array}$ & $\begin{array}{c}-1.008^{* * *} \\
(0.000)\end{array}$ \\
\hline Strategy and Year FE & Yes & Yes & Yes & Yes & Yes & Yes \\
\hline Observations & 5,983 & 5,983 & 6,347 & 6,347 & 6,425 & 6,425 \\
\hline R-squared & 0.511 & 0.458 & 0.456 & 0.271 & 0.129 & 0.121 \\
\hline
\end{tabular}

